\title{
Nit?!CE
}

PORTIGN OI

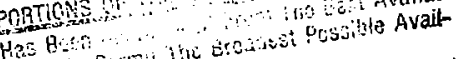

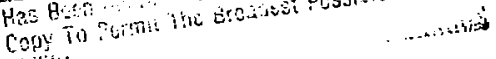
ability. 
CONTENTS

SURVEYING PROCEDURES . . . . . . . . . . . . . . . . 4 4

I. Introduction.................. . . 4

II. Ring Surveying - Laser . . . . . . . . . . . . . 4

III. RF Cavities - Laser Surveying . . . . . . . . 25

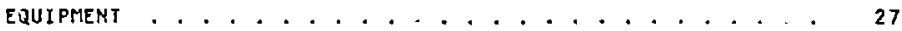

I. Fixtures................... 27

A. Bend Magnet Fixture ............ 27

B. Quadrupole Magnet Fixture ............ 30

c. Sextupole ragnet fixture ............ 31

D. Insortion Quadrupole Fixture.......... 32

E. Quadrupole and Sextupole Roll fixtures....... 33

F. One-Inch fooling Balls.............. 33

II. Tunnel Monuments ................ 33

A. Installation of the Monument pin......... 33

B. lonumant cleaning .............. 34

I1]. Liquid Level system ................ 35

A. Liquid Level System Harduare and Instaliation... 3ú

B. Liquid Level Calibration............. 38 
IV. Optical Tooling and Equipment ............ . 47

A. Optical Instruments ............. 47

B. Optical Tooling Scales............... 48

c. Optical Tooling spheres ............. 48

v. Laser Equipment ................ . 49

A. Laser Unit................... 49

B. Optical Translater............... 51

c. Laser Target. . . . . . . . . . . . . 5 ?

VI. Automatic Readout Instruments . . . . . . . . 52

A. Small Automatic Micrometer (SAM) and Liquid Level Rods.................. 52

B. Rutomatic Readout Micrameter (ARM) and Standard gage ................ 53

c. Automatic Readout Tape Unit (ARTU) and Extension Tapess ............... 55

VII. Magnet Roll Instruments .............. 58

A. Injection Magnet Roll fixture ......... 58

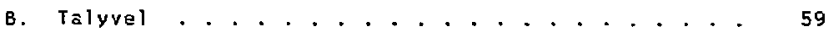

REfERENCES . . . . . . . . . . . . . . . . . 63

figures .............................. G4 


\section{SURVEYING PROCEDURES}

\section{Introduction}

The PEP Survey and Aligunent System, designed by $R$. $C$. Sah and $T$. Lauritzen of Lawrence Berkeley Laboratory, employs both iaser-jased and optical survey methods. The laser is operated in conjunction with the rektronix 4051 computer and surveying instruments such as ARH and SAM, a system hhich is designed to automate data input, reduction, and production of alignient instructions. The laser systen is used when strveying ring quadrupoles, main bend magnets, sextupoles, and is optional when surveying Rf cavities and insertion quadrupoles.

Optical methods usually require that data be manualiy entered into the computer for alignment, but in sone cases, an eiement can be aligned using nominal values of fiducial locations without use of the computer. optical surverying is used in the alisnment of NIJ and SIT, low field bend magnets, wigglers, Rf cavities, and insertion quadrupoles.

\section{Ring Surveying - Laser}

ouring PEP construction, 17 survey and al ignent monuments were cast into the iloor of each of the ringss six arcs. Moving clockwise around the ring, starting at the beginning of region one ( $\left.120^{\prime} \mathrm{clock}\right)$, the monuments are numbered 201 on up to 302 . Each m.cnument indicates the siarting point of a "sector," which ends at the following monument. The sector number is the same as the number of the beginning monument. The components within a typical ring sector include three concrete rafis on which rest three quadrupoles, three sextupoles, two complete benc magnets, and one-half of a bend at the start of the sector and a half at the end (the other halves of the bend magnets are consicised to be part of the neighboring sectors?. Other seciors in the ring may differ irom this; they may include low-iield bend magnets, wigglers, RF cavities, insertion quadrupoles, or no magnets at all.

Alignment proceeds one sector at a time: under directior of program MEASLRE, the elements of an entire sector are surveyed, after which MEASURE prints out the results of the survey and the changes to be made in all of the stands in the sector. The foilowing outline (Table I) is a suggested routine for two surveyors to iollow in measuring a ring sector. (Following the table, specific procedures will be elaborated.) We begin with the cart and trailer at the proper sector: 
Table I. Suggested Routine in Measuring a Ring Sector

\section{SURVEYOR A}

SURVEYOR 8

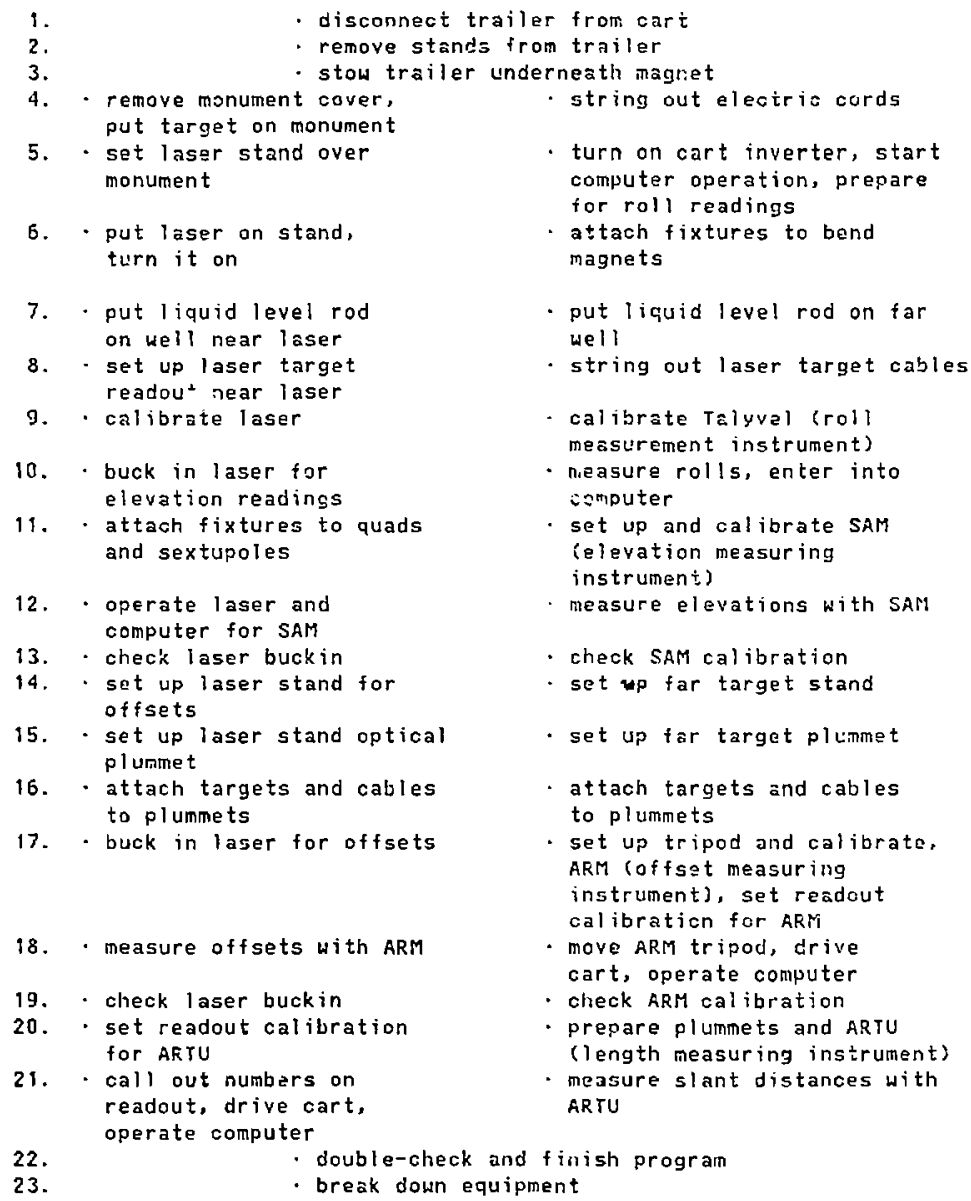

22.

- double-check and $f$ inish progran

23.

- break down equipment 
Surveying Procedures in Detail

iR, 5R] Set laser stand over monument target:

The laser is used during elevation and offset measurements. The losation of the laser is not important for elevations - it may be in any position that will permit sighting of both liquid level rods and effective buckin. However, since the laser stand losation is critical for offset measurements, it is best to correctly pasitian the stand before elevation measurements so that it will be unnecessary ta moye it later.

It is possible to place the laser over either monument, but the preferred monument has both liquid levels to one side of it, Generally, one monument in a sector will be so positioned; the other would ije just inside a liquid level well. The postion of the iaser is important for the following reason. The laser turret rotates from pointing at one liquid level to the other curing elevation buckin and measurement. If this angle is reduced, inaccuracy caused by turret movement will hava less chance of afferting the surveying. When both liquid level wells are to one side of the laser, the maximum angle swept is approximately 45 degrees, wherea: the alternate laser position requires a sweep perhaps tuice that.

The laser stand is leveled, pointed correctly, and roughly centered over the optical tooling sphera:

1) Remove the monument lid.

2) Clean the monument well of water, debris, dirt. clean espeoially carefully the stainless steel post and its base.

3) Slip on the optical tooling sphere cup and set the optical tooling sphere on it.

4) Roll the laser stand to the approximate position over the target, so that the optical plummet mount is between the laser slide and the far monument.

5) Lowar the stand off its whels.

6) Referring to the bubble level on the compound slides, level the stand hy turning the screws in its base. When the stand is level, check to make sure that all three wheeis are off the floor. Tighten the leveling screws' locknuts.

7) Adjust the position of the stand over the target so that: a) the three white lines painted on two of the legs and the center center post converge on the center of the target, and b) the laser mounting plate points at the far monument (sight along the edge of the plate to the stand over the far monument). 
8) Recheck that the stand is level. These steps are necessary to avoid time-consuming problems ater when bueking in for offset measurements. If the stand is not carefully pointed, the laser slide may run out of travel trying to compensate for itie misa) ignment. The stand would then need to be moved and the plumet releveled and recentered.

58] Turn on the cart inverter, start computer operation, prepare for roll readings:

After the cart battery charger has been plugged intc a wall outlet and is charging, the inverter may be turned on. The laser box should be removed from below the inverter since it will impede the air flow to the inverter cooling fans. Any of the ather elictronics may then be turned on as needed.

Switch the computer on. The "POWER" light should turn on and the cathode ray tube (CRT) should glow. After a monent, press the "HOME PAGE" button to clear the screen. A blinking cursor in the ufper lefthand corner signals that the conputer is ready to accept a command. Iurn on the Texas instruments silent 700 terminal. The toggle switches should be set at "high-speed", "full duplex", and "on-l ine".

To prepare the computer to accept rall readings:

i) Insert program tape "MEASURE 5.4", or the most current version MEASURE.

2) Type in fINO 4 (push return), OLD (return), and kUN (return), or push the "AUTOLOAD" key. Rutoload locates the first program lacates the first program on the tape (which is on file four in this case) automatically loads it into the memory, and runs the program.

3) The remaining procedure is directed by MEASURE: the computer operator enters information about the run, inserts the input data tape, and is given options concerning data input and outiput. The program tape is inserted and overlay 1 of MEASURE is fed into the memory. The computer is now ready to accept surveying data.

6A] Set the laser on the stand and turn it on:

Before the laser is put on its single slide, check the screws on the blue mounting plate and on the stand for tigntness: remove the laser mounting plate and check the 4 socket-head screws that hold the chrome ring onto the compound slide, and replace the laser mounting plate and check the socket-head screws that attach the securing lever to the plate. 
Set the laser on the slide, centering it widthwise. Allow at least $1 / 8$ inch clearance between the laser housing and the mounting plate. Turn on the two switchable permanent magnets. The laser should receive current from the tunnel power supply, not the inverter. Turn on the laser. If a red light does not soon appear in the housing cooling holes, switch it off and on again. Roughly level the laser, using its coarse adjustments.

\section{8] Attach fixtures to bend magnets:}

For directions concerning the proper use of the bend magnet fixtures, refer to the section on equipment. The quadrupole and sextupole fixtures are not attached until the roll measurements have been taken.

7] Install liquid level rods on wells:

1) Examine the liquid level well for looseness or evidence that it or the micrometer has been moved from its original position. check the number on the micrometer's digital readout against the labeled number on top of the well. If the label is missing refer to the latest entry in the liquid level log book. Set the micrometer to the correct reading, if necessary.

3) Attach the "flex-o-post" indicator holder to the liquid level rod steady-rest arm.

4) clean off the bottom of the rod and put it on the micrometer tooling ball.

5) Attach the flexible holder magnet to the iron of a ring magnet, or to a steel plate on a tripod.

6) Plumb the rod and tighten the clamp on the flexible holder.

7) Loosen the steady-rest thumb screw and ratate the rod so that the target is pointing at the laser. Tighten the thumb screw.

8) Attach the grey cable to the laser target.

9) Check that the target is fully inserted in the collar, that it is correctly rotated, and that its lock screw is tight.

10) Recheck that the rod is plumb.

SA] Calibrate the laser:

This procedure is not so much a calibration as an adjustment of the laser optics. Each time the laser is switched on, the beam exits from a slightly different point in the laser optics system. It then passes vertically into a rotatable prism that reflects the beam horizontally. If the vertical beam does not exactly coincide with the turret (prism) axis of rotation, it will be reflected horizontally at slightly different elevations as the turret is rotated. Therefore, each time that the laser is turned on, and if the turret is to be moved during 
surveying (as in elevation measurements), the beam must be centered on the turret axis. Calibration is not required if only offsets are to be taken.

1) Plug the short laser target cable into the top of the nearby target box. The toggle switch in the rear of the box should be pointed at the correct connector.

2) The laser should be warmed up. Turn the target box cn and switeh it to "fast response".

3) Narmally, the two blue rectangular knobs on the rear of the turret will be pointing to 3 ofclock. This is the mode in which surveying is done. For calibration. first turn the left knob to 12 aclock. This moves the internal prism off to the side, and the beam should exit the vertical aperture. Then turn the right knob to 12 o'clock. This moves an internal photoelectric target down over the beam, which registers on the readout.

4) Rotate the turret to first position (12 0/clock): a slot-head incex screw should face the center of the laser's long-side bubble level.

5) Zero the readout's horizontal and vertical scales by using a $3 / 32 "$ allen head screidriver to turn the set screus located inside of the two holes in the short side of the laser housing. below the bubble level.

6) Rotate the turret 980 degrees to the second position ( 6 o'clock).

7) If either the horizontal or vertical reading is greater than $.01 \mathrm{~mm}$, halve it using the adjustment screws.

8) Rotate the turret 90 degrees to third position ( 9 o'clock).

9) The horizontal and vertical scales are now reversad. halve any readings as before.

10) Rotate turret 180 degrees to fourth positinn ( 3 o'clock).

11) If the readout values aren't yet within $.01 \mathrm{~mm}$, agair. halve them.

12) Check that all orientations of the turret give acceptabie readings.

13) Turn the internal target knob to 3 o'clock. Turn the prism knob to 3 o'clock. The laser is again in strveying mode.

9B] Caliurate Talyvel:

Calibration of the ralyvel insures that we have an absolute zero roll angle reference, that the pointer readings are equal to readings taken in the null mode (pointer at 0 and reading taken from the leveling knobs), that there is sufficient battery power, and that the electrical balance is correct. Use the Talyvel instruction mandal for further reference to the following calibration procedures:

1) Remave the level unit from the back of the Talyvel meter unit. Leave the back open.

2) Plug in the level un: $t$. 
Unscrew the leveling knobs to 0 : two short gradient graduations are visible on the micrometer barrel and one long graduation is jusi visible underneath the leveling knobs, which are turned to register o on the scribe on the barrel.

4) Check the battery voltage:

a) The range switch is at any setting (including off).

b) Press the battery switch in back of the meter unit.

c) The meter needle should regisier to the right of the reb square on the face of the meter.

d) Replace batteries if the needle doesn't reach the red square.

5) Check electrical balance:

a) Place the level unit on a stable surface.

b) Turn the zero adjuster to point at the black mark.

c) Range is 100 sec.

d) Use the leveling knobs to zero the pointer.

e) Press the BALANCE suitch.

f) The needle should move to the right four to five divisions.

1) Unscrew the balance dummy knob.

2) While pressing the balance switch, simultanenusly turn the balance adjuster screw and the leveling knobs to take the needle as far to the right as possible (if the meter has been zeroed correctiy in step $d$, the ieveling knobs will already be at their optimum positions).

6) Adjust meter zero:

a) Range at any setting except off.

b) Press the meter zero suitch.

c) Turn the zero adjusiment knob to zero the needle (ganerally, the zero position of the knob is slight)y to one side of the black riark).

7) Cheak the level unit zero:

a) Set the level unit on an adjustable surface plate, such as the bend magnet fixture roll plate. Maxe sure that the plate and level unit surface are very clean. "Wring" the unit onto the plate.

b) Set the leveling knobs to 0 .

c) Set the range to $100 \mathrm{sec}$.

d) Adjust the plate by turning the micrometer untit the meter reads 0 .

e) Reverse the level unit. The meter shouid still read within one unit of $a$. If not:

1) Repeat steps a-e to verify the discrepancy.

2) Haive the meter reading by turning the penduluin zero adjuster screw through a small hole in the side of the level unit.

3) Reverse the level unit and repeat the proceduie stariting at step d.

8) Gain calibration:

a) Set the level unit in a flat surface.

b) Set the range to $8 \mathrm{~min}$. 
c) Set one leveling knab to 0 .

d) zero the meter by turning the other knob.

e) Turn the knob set on 0 ten divisions (to the line marked 20 the needle should move to the last major division marked with red and green values ( $2 \mathrm{~mm} / \mathrm{M}$ or .002 in/in). If not:

1) remove GAIN dunny knob.

2) Turn gain adjuster screw until the needle reads correctly.

f) Turn the leveling knob back to 0 and then on to 20 on the other side of the scale - the needle should read at the opposite end of the meter's scale at .002 insin. If not, repeat step e.

10] Bucking in the laser - general principles:

There are two requirements for elevation and of iset buckins. first, the two targets must be at greatly unew'al distances from the laser or optical instrument ("near" and "far" iargets), and second, the instrument is translated when "sighting in" the near target and rotased to center on the far target.

Translation means moving the instrument parallel to a:ly fixed axis. During elevation buckin, this is done by adjusting the elevation screw of the laser stand, and in offset buckin, the laser is translated by adjusting the compound slides or the optical beam transiater. Rotation means changing the angle of the laser beam and is done by adjusting the levei screws of the laser or by turning its turret.

This buck in method works only when one target is much nearer than the other. If the iaser is vertically centered on the near target (one meter from the laser, for instance) and the far target (100 meters away) is low by $100 \mathrm{~mm}$., vertically rotating the laser to center on the far target wiil cause the near target to appear too high by only about $i \mathrm{~mm}$. Then, the laser is raised about $1 \mathrm{~mm}$. to center on the near target, which causes the far target to appear $1 \mathrm{~mm}$. too low. The laser beam is rotated to center on the far target, meanwhile causing a location error at the near target of only .01 $\mathrm{mm}$. The laser is further translated and rotated as required to reach a sufficientiy accurate buckin. (since during elevation measurements there is no requirement for a horizontal juckin, the laser turret is ratated to horizontally center on both near and far targets.)

\section{[0A] Buck in laser for elevation measurements:}

The laser buckin for elevation measurements places the laser at the same height as the two liquid level rods' laser targets, providing a level swept plana at a knosin elevation. Vertical measurements are taken between this pla.le and the magnet fiducials using SAM. Aiter the laser has been calibrated: 
1) Connect by cable the nearby laser target readout box to both liquid level rod targets. The readout may be set to fast response.

2) Roughly level the laser before the stand is raised.

3) Check that the stand's fire elevation screw adjustment has about $1 / 2$ " travel in either direction.

4) Raise the laser stand so that the beam enters the cenier of the nearby laser tarjet. Set the target readout toggle switch to register the beam.

5) The other surveyar should point the target correctly by revolving the liquid level rod and target until the beam enters the target shade squarely. There should be no orescent-shape shadow inside the target caused by bean cut-off by the shade. At the same time, the laser operator must rotate the turret to point directly at the target. Tighten the liquid level rod rod lacking screw and check that the rad is plumb.

6) Lock the stand's rough adjustment lever.

7) Level the laser in two directions using the coincidence bubble levels. If a flashlight is needed, it must be at least one foot away from the bubble and operated intermittently to prevent the buildup of heat in the vial.

8) Use the stand's fine elevation adjustment sarew to bring the laser to a height where the beam registers " 0 " on the vericical scale of the readout. Keep the horizontal reading near "O" by turning the turret $w i$ th the turret azimuth adjusting screws. 9) Relevel the laser using the coincidence bubble levels.

NOTE - Both laser bubbles are precalibrated with respect to the beam in the lab, but transport and use of the laser causes the vials to fall slightiy out of adjustment. Therefore, in the mosi critical direction along the PEP beam line - we use the liquid levels as an elevation reference, and not the longituiinal laser bubble (the one parallel to the beam), although it usually is close. The longitudinal bubble, then, is not perfectly centered when bucking in the laser, and it will change during the completion of this procedure.

The transverse bubble (perfendicular to the bean line) is our only reference in that direction. Since the fidicials from which measurements are taken are close in line with the liquid level rods, the levelness of the transverse direction is not critical and we have no need of external elevation references. However, the transverse bubble should be as clasely centered as possible before elevations are started, and it should be checked and adjusted during the measurements.

10) Repeat steps 8 and 9 (raising or lowering the stand and releveling it) until the laser is transversely level and close to leve $i$ longitudinally, and the readout registers "g" an the verticai scale.

i1) Switch the target readout bcx to register the far target. Switch to "slow response" if necessary. 
12) Point the turret at the far target. If the longitudinal bubble is level, the beam will be slightly above or below the center of the iarget (usually by less than one millimeter).

13) Rotate the far target to align it. check that it is plumb.

14) Center the jean horizontally using the turret's fine azimuth adjustment screw.

15) Turn the laser's longitudinal fine level adjustment so thet the readout's vertical scale is "o".

16). Rotate the beam back to the near target. Use tha laser stand's fine elevation adjusting screw to translate the beam vertically so that it registers " 0 " on the target readout's on the target readout's vertical scale.

17) Repeat steps 11 through 16 until the beam is vertically centered on both targets.

18) check the levil of the transverse bubble.

NOTE - The optical beam translater is not attached for elevation measurements because it is easily disturbed when the turret is rotated.

10B] Take roll measurements, enter them into computer:

Bend magnet rolls (Fig. 1):

1) The Talyvel should be calibrated and set on the 8 minute scale.

2) Check that the bend magnet fiducial fixture's micrameter reading corresponds to the number stamped and written on the magnet above the fixture.

3) Clean off the fixture base plate and the Talyvel ievel unit base.

4) Clamp the level unit onts the fixture with the cord on the aisle side. "Wring" the unit onto the plate.

5) Check that both leveling knobs are set to 0 .

6) Take meter readings:

a) The reading is positive if the needle is to the right of $D$, negative if to the left.

b) Take reading values from the inches/inch scale - it is the top green scale.

c) Each small divisian equals .0001 in.tin. and each major division equals .001 in.tin.

d) The meier can register a maximum of $\pm .0025 \mathrm{in.jin.,} \mathrm{which}$ is adequate for nearly all of the ring magnets.

e) The meter reading is typed into the computer - for instance "-.0013". The program assigns to the input valve units of radians instead of in./in., but the two units are equivalent when measuring the small roll angles found in the ring magnets. 
Quadrupoie and sextupole rolls (Figs. 2 and 3 ):

1) clean of the ears or the ear clamps on the magnet.

2) Install the roll fixure. Check that the quadrupole clamps do not interfere with the fixture, and that all tinree fixiure feet are resting on the ears.

3) Clamp on the level unit with the cord on the aisle side.

4) Check that the leveling knobs are on 0 .

5) Take the reading and enter it into the computer.

6) Sextupole rolls will tend to be larger than those of the other magnets, and the meter may occasionaliy go off scale

(roll) \pm .0025 in.tin.).

In this case, measure the roll in the following manner:

a) Note whether the reading is + or -.

b) Turn either leveling knob until the needie returns to 0 . Note the numbering of both upper and lower scales of the knob; use the scale on which the numbers increase as the knob is being turned.

c) Each small lined division is .0002 radians. "10" represents . 0010 radians. Should more than one revolution of the knob be necessary, make sure that the knoo is being turned in the right direction to zero the needle. Each tirn exposes a a cradient graduation on the knob barrel's vertical scal. which reprisents 0100 radians.

d) When the nuedle is zeroed, take the reading.

e) Double-check the roll by taking the reading ag..in.

7) After all the roll measurements have been taken, turn off tice Taivvel meter unit, screw doun the leveling knobs and put the leveling knobs and put the level unit into the case.

11A] Place fiducial fixtures on the quadrupoles and sextupoles: See the section on equipment for instructions on proper fixture placenent.

I18] Set Up and calibrate SAM:

1) Connect the SAM Cable to SAM and the blue box.

2) Insert the laser target into SAM. The target wi?l click into place when it is correctly oriented "up". Attach the coiled target cord to the SAM body.

3) Turn on the Mitutoyu readout. Its suitches should be set at $\mathrm{mm}$. and direction = up.

4) Check the calibration pre-set number on the readout against the number labelled on SAM. Each SAM has a different calibration number. 
5) Turn SAM's micrometer until the third black line on one of the steel rods at the bottom of SAM has just appeared. Continue turning the micrometer until the 0 on the thimble itnes up with the 1 ine on the barrel.

6) Push doun the preset switch on the readout. The digital display should give the calibration number.

7) To double-check the calibration, turn the miorometer several times in either direction, and then bring it back to the calibration position described above. Check the display's number.

\section{2,13] Measure elevations:}

One eres member adjusts the laser to horizontally center the beam in SAM's target, as well as operates the computer and drives the cart while the other operates SAM and calls out horizontal target reaciout numbers if they can not be seen at the laser.

1) The computer is ready to accept elevation readings.

2) Push user key 10 - four ligits should go on:

a) the green light on top of the cart's tarset readout

b) the red ready light on the blue box

c) the red ready light on the Fairchild instruinent coupler

d) the conputer 8USY light

3) Prepare SAM for readings (Fig. 4):

a) 2.ttact the flexible holder to SAM.

b) Piace sall on the correct fiducial.

c) Attach the flexible holder to the ring magnet (the neck's clamp should be loosened and adjusted).

d) Level SAM.

e) Tighten the clamp while keeping its slide attachment to SAM in the middle of $i$ ts travel. SAM should be secureiy held but free to travel vertically as the micrometer is turned.

f) Point SAM arget at the laser.

4) Turn the cart's target readout so that the Srim operator can see it. If the laser operator can not read the horizontal scale numbers, the SAM operator must call them out ( $F i g .5$ ).

5) The SAM operator raises or lowers SAM and helps the laser operator to approximately center the beam in the target. Aim SAM's target.

6) The laser turret is rotated by hand or by use of the coarse the coarse and fine azimuth adjusting screws. Each sorew should be in the middle of its travel.

7) SAM is raised or lowered until the vertical reading is 0 . The horizontal reading should be within $\pm .20 \mathrm{~mm}$.

8) Check that the beam esters the center of the target and that SAM is level.

9) Push SAM's input button. This feeds the distance from the center of the tooling ball to the center of the target into the computer. This number appears in three places: the Mitutovu 
readout (to one extra place), and after the button is pushed, on the computer screen and on the silent 700 printaut.

10) The laser oporator checks the input elevation and the eleyation error ( $d E$ ) to sea that they are close to the expected values (i.e., not off by $1 \pi$ : :er).

11) Set SAM on the next fiducial and continue eleyation readings in the preceding manner.

12) Periodically, in between readings, check and adjust the laser buckin, especially if it seems to be unstsble.

13) After the last reading:

a) check SAM's calibration to $\pm .1 \mathrm{~mm}$.

b) Cheok the laser buckin to $\pm .3 \mathrm{~mm}$.

c) If either of these tolerances are exceeded, try to determine where in the sector the calibration or buckin lost accuracy, and repeat the readings from there (input as dE's all of the of the correct measuremenis). Otherwise, repeat the readings over the entire sactor.

d) clieck that the silent 700 legibly printed out all of the numbers. If not, use the program's reprint option to print out the dE's.

14A] Set up lasar stand for offset readings ( $F i g .6$ ):

The offset measurement reference line is directly above the conter of the sector's two munuments and at the average ficucial height. Here, we are primarily interested in bucking in the laser horizontally, but sinse it is not designed to sweep a vertical angle, we also buck it in vertically. The reference points that determine the line are the near and fai plummets, which are leveled and centered at magnet fiducial height over optical targets in the monument wells.

1) Carefully lower the iaser stand so that the laser is at fiducial height.

2) Lock the stand's elevation adjustmant.

3) Check that the stand is closely located over the center of the monument target and that it is pointed at th: far stand (see 4A, step 7).

4) Attach the optical translater and straighten out its elements.

5) Set the laser plummet on the stand.

6) Roughly level the laser.

7) Point the laser at a nearby magnet fiducial ball and adjust the stand's elevation using the fine adjustment screw until the bean is o: the middle of the ball.

8) Point the laser at a far tooling ball. The baam should be within a half inch of the ball if the laser is level. Split the diffe, ence in fiducial elevation using the stand's fine vertical screw.

9) Set the optical tooling sphere on the laser plummet facing the laser. 
10) Roughly level the plummet at the height where the beam strikes the optical target in the center. If this step is omitted, the plummet might be leveled and centered at tos high or low an elevation for the optical translater's vertical adjustment. The plummet would then have to be readjusted beiore the continuation of the buckin procedure.

i1) Remove the optical target and place it on the monument.

12) Aim the laser at the far plummet's iarget for an elevation reference for the iar stani.

146] Set up the far stand for of fsets:

1) Center and ievel the stand over the far monument target. check the lacknuts. There is no need to point this stand.

2) Set the plummet on the stand.

3) Put the optical tooling sphere on the piumnet, facing the laser.

4) Adjust the stand's elevation so that the beam strikes the target's center.

5) Lock the stand's elevation adjustment.

6) Place the optical target on the monument.

15] Level and center plummets (Fig. 7):

1) Loosen the plumiet's rotational locking nut.

2) Set the plummet on the stand.

a) Point the telescope in tlie direction of one of the adjusting screws.

b) Center the bubble (don't use the coincidence bubble yet) by turning the adjusting serew.

c) Rotate the plumme $\$ 90$ degrees so that it is parallel to the line between the other two screus.

d) Level the plunmet in this direction by turning the two screws in opposite directions. The bubble will move in the same direction as the left thumb.

3) Roughly center the plummet:

a) Rotate the monument's optical target so that its pattern is aligned with the angle of the cross slides.

b) Rotate the plummet until the cross hairs are lined up with the target's grid. Focus the plummet ard sharpea its cross hairs using the reticle adjustment.

c) Adjust the compound slides to center the plummet on the target to within $1 \mathrm{~mm}$. or so.

4) Find the plummet bubble's calibration:

In general, the plummet's bubble is not perfectly calibrated; that is. when the coincidence vial registers level, the plumet's horizontal rotational plane is out of level by a small amount. The following procedure finds the relative position of the two 
halves of the coincidence bubbie that indicates that the plummet's rotational plane is level.

a) Point the telescope at one of the adjusting screws.

b) Center the bubble using the coincidence vial.

c) Rotate the plummet exactly 180 degrees and let the bubble settle down.

d) Observe the vartical distance between the menisci on either half of the coincidence vial (a meniscus is the dark band surrounding the bubble). If this distance is greater than 2 or 3 menisci widths, the plumnet bubble needs to be recalibrated (see the section on plumet calibration).

e) Turn the screw with which the plummet is aligned until the distance between the menisci is halved. Hote the new distance and on which side of the vial the bubble is high.

f) Ratate the $p$ lumriet $i s 0$ degrecs (back to its original pasition). The bubble should be within one-half meniscus of the same position as before the rotation.

g) If not, turn the screw until the difierence in the distances is halvad.

h) Repeat steps $f$ and $g$ until the bubble position is within onehalf meniscus of being the same at 0 and 180 degrees. This position is the "level" position of the bubble, and it indicates that the plummet is level along that line.

5) Levei plummet:

a) The plummet bubble "level" has been found and, additionally, the plumet is level along that line. Now, the plurmet must be leveled along the perpendicular direction. Turn the plummet 90 degrecs. The telescope is now faraliel to the iwo other adjusting screws.

b) "Level" the bubble by turning in oppasite directions both adjusting screws.

c) Rotate the plumet 90 degrees to its original position. Relevel the bubble.

d) Repeat steps a-c until sufficient accuracy is achieved. check that the bubble is within one-half meniscus of the same position at all orientations of the plummet.

6)

Center the plummet:

Due to limitations in the manufacture of the plumiset, the optical plunb can not be made to be perfectly perpendicular to the horizontal plane of rotation. Therefore, when the plummet is leveled and rotated about its vertical axis, the cross-hairs will sweep a circle on the monument target. To correctly position the plumet, tive skept circle, not the cross-hairs, is centered on the target.

a) Focus the crous-hairs and tile target inage.

b) Align the pluminet cross-hairs to the target grid,

c) Adjust the compound slides to center the cross-hairs over the target.

d) Rotate the plummet 180 degrees.

e) Adjust the compound slides to halve the distance between the center of the cross-hairs and the center of the target. 
Note the position of the cross-hairs on the target.

f) Rotate the olumet 180 degrees. The cross-hairs should be at She same relative position on the target as in step e.

g) If not, repeat steps e-f, halving the difierence in position each time. Generally, one iteration is sufficient if the plummet has been closely centered to begin with.

h) Clieck the pluminet's position and levelness in all orientations.

16A] Prepare the laser stand plummet for offset readings:

1) Lock the plumet rotation screw.

2) Put the laser target safety chain around the stand and place

the laser target on the plummet.

3) Connect the cable between the target and the laser target readout (not the readout on the cart).

4) Point the laser at the target.

5) Level and point the target and rotate it to the "up" position.

NOTE - The weight of the laser target will appear to throw the plummet out of adjustment. The bubble will not be level and the cross-hairs will be uncentered. Huwever, the main eifect of the weight of the target is to slightly bend the plate on which the plumet rests. This movement is insignificant since the cluange in the horizontal position of the plumet is very small. Rocheck plunget positioning only with the laser target off.

16в] Prepare tine far stand plummet for offset raadings:

This pracedure is the same as described above, except ihat the target is clamped to the plummet.

17A] Buck in the laser for offset readings:

1) The laser should be fairly level, and the target should be off the laser stand plummet.

2) Switch the target readout to "slow response" if necessary. The toggle switch in the back of the box is set to register the far target.

3) Point the laser at the far target.

4) Rotate the laser to center the beam in the far target ( $\pm .20 \mathrm{~mm}$, the first iteration, $\pm .01 \mathrm{~mm}$. thereafter).

a) Vertical beam rotation: use the longitudinal level adjusting screws to raise or lower the beam.

b) Horizontal beam rotation: rotate the laser turret by hand or with the azimuth adjusting screns. 
5) Switch the target readout to register the near target. Use "fast response". Put the target on the near plummet.

6) Translate the laser to center ( \pm .0 / m.n.) the beam in the near target:

a) Vertical beam translation: only the optical bean translater can be used, and since it has a limited range of adjustment, it is impo tant that the plummet has previously been set ciase to the corlect height. If the horizontal transiation knob hits the top of the translater frame as the bean is being raised, rotate the knob and glass 180 jegrees down past the front of the beam so that the unob is below the glass where it won't interfere. This allows an additional amount of vertical adjustment.

b) Horizontal beam translation: use the laser slide for adjustments greater than 1-2 ma. Use the optical transiater for for fine adjustment.

NOTE - Althouch the optical beam transiater elements rotate, the parallel air-glass and glass-air surfaces refract the beam equally and in opposite directions so that the net result is a beam offset in the direction of the glass rotation, with no change in the angle.

7) Renove the near target and switch the tarjet readout to register the far target.

8) Repeat steps 4-7 until the readout shows the laser is horizontally bucked in to within. $01 \mathrm{~mm}$. The vertical buckin should be within . $10 \mathrm{~mm}$.

17B] Set up and calibrate ARM and set up the ARM tripod:

1) Turn on the Ideal-Aerosmith readout.

NaTE - ARM and ARTU share two someuhat different Ideal-Aerosmith digital readouts, the "KIII" and the "gigit-Read 8000". The round knob on the iront of the KIJI is set to M for metric. The switches in the back of the KIII are set to REV and $1 X$ and are never changed. The switches on the front of the 8000 are set to HI and METRIC, and the directional suitch is set to the left position. Push the 8000's warning reset button to stop the blinking display (an interrupt warning).

2) Set the readout's preset dials to the number labeled on the ARM calibration tixture.

3) Insert the adapter ring into ARM's target holder.

4) Place ARM in the calibration $f$ ixture.

5) Connect the ARM-ARTU cable to the blue box and to ARM.

6) Use the coarse adjusting wheel to extend ARM to its maximum length. While continuing to turn the wheel (it will silp when ARM reaches its maxinum extension in the fixture), push the readout's preset button. The readout should display the correct 
calibration number. Releasing the wheel before the preset button is puslied will permit ARM to relax, causing a calibration error of a few hundredths of a $\mathrm{mm}$.

7) Set up ARM leveling tripod:

a) Erect the tripod anc mount the adjustable tooling plate.

b) Place the tripod near the firs: fiducial in the sector.

c) Tighten the elevation locking knob until the tripod coiumn can be raised or lewered only with some resistance.

d) Turn the tripod until its legs are out of the way of the ARM operator.

e) Loosen the tripod head rotation locking knobs and turn the tooling plate to place the bubble level in the aisle. Lock the head rotation knobs.

18] Take offset readings (Fig. 8):

offset measurements are taken with ARM perpendicular to the beam $l$ ine and at iaser beam elevation.

1) The cart's target readout may be on fast or slow response, depending on conditions and ARM's distance from the laser.

2) Push User Key 10 to enable the computer to accept ARM inpui.

3) Into ARM's target holder insert and correctly orient "up" the iaser target. Attach the coiled target cable to fRM.

4) While one surveyor supports $A R M$ and places $i t$ on the magnet fixture's tooling ball, the other surveyor adjusts the position and elevation of the leveling tripod so that:

a) ARM can arc on the tooling plate several inches in either direction irom its position perpencicular to tha beam line.

b) ARM's target is at the same haight as the beam.

c) The adjustable tooling plate is level.

5) Rest ARM on the plate. Always keep one hand on ARM.

b) Extend ARM to intersect the beam line.

7) Adjust the tripod to bring ARM to approximately the right elevation. Steps 6 and 7 should be checked visually.

8) Adjust ARM to the correct position: Before an input sigral is sent to the computer, ARM must be perpendicular to the laser beam line and the beam must be horizontally centered in the target. Note that the offset reading is at right angles to line of the laser (or monument $l$ ine), not to the line of the magnet or to the PEP beam line. To find the required perpendicular direction. ARM is arced back and forth through the beam. The cart's target readout indicates where on the target the beam is hitting. As ARM is arced, the following numbers might might be seen on the horizontal scale, deperding upon the laser setup and ARM's length: (The readout's vertical scale should be kept to within $\pm .15 \mathrm{~mm}$. during this procedure by adjusting the leveling stand elevation,) 
a) The perpendicular is approached: large positive numbers begin to decrease as the beam "moves" from the outer (ais)eside) edge of the target towards the inner (fiducial-side) edge.

b) ARM is perpendicular to the beam: The readout numbers reach a minumum value as the bean stops moving inward and begins to move uutward again. This ninimum number will be negative if ARH is longer than its ideal length (the beam is striking inside of the median line of the photoelectric cells) and it will be positive if ARM is too short (the beam never reacies the center of the target as ARM is arcad).

c) The perpendicular is passed: The readout numbers begin to increase as the beam moves to the aisle-side of the target. If arcing is colitinued, the bear will start to hit outside of the beam will start to hit outside of the target and the readout numbers will begin to drop. Therefore, irequently check that the beam is completely in the target during arcing.

NOTE - As you face the laser target, the positive-value signalling photocells are on the left and the negative cells are on the right. If the laser is on the lower-numbered (downstream) monument, ARM is oriented such that the positive cells are on the aisle-side of the target. Therefore, as ARM is arced, the readout numbers will go from higher values to a minumum, as in the example above. If, on the other hand, the laser is set up on the higher-numbered (upstream) monument, the negative cells will be in the aisle, and the procedure outlined above will have all of $i$ ts signs reversed, that is, the readout numbers will go from low values (they may be large negative numbers) to a maximum (negative if ARM is tos short and positive if ARM is too long) and then back to low numbers as the perpenoicular is passed.

d) The correst position of ARM, perpendicular to the beam line, is found when the readout number is at a minimum, if the laser is downstream of ARM, or at a maximum, if the laser is upstream of ARM.

9) Adjust ARM to the correct length:

a) Find ARM's position perpendicular to the beam line.

b) Center the target on the beam by adjusting ARM's length using the coarse and fine wheels. The readout's horizontal scale will show $0.00 \mathrm{~mm}$. When the target is centered.

10) Take the offset reading:

a) Repeat steps 8 and 9 , arcing and adjusting ARM's length, until the minimum (or maximum) value is $0.00 \mathrm{~mm}$. ARM is now perpendicular to the beam and at the correct length.

b) Check that the beam is in the target.

c) Push the input button.

d) Check the input of fset reading and the offset error (dF).

i1) Move ARM and the tripod to the next fiducial. 
12) After the last of fsat measurement, check that all of the incut values have been printed out legibly by the silent 700 . Reprint $d \bar{r}^{\prime} s$ if necessary.

\section{A] check the laser buckin:}

check the laser buck in at the near and far targeis. The horizontal buck in s!ould be within $\pm .05 \mathrm{~mm}$. (if canditions permit). If the buckin is out of tolerance, recheck a few offsets to determine where in the sector accuracy was lost. Repeat offset measurements from there.

\section{6] check ARM calibration:}

1) Carefully remove the laser target from ARM.

2) Insert the adapter ring into ARM.

3) Place ARM in the calibration ixture.

4) Extend ARM to its maximum length. While continuing to turn the wheel, check the calibration number. It should be within $\pm .10 \mathrm{~mm}$. of the correct value. If not, see step 192 above,

5) Put ARM back in its case.

20A] Preset Ideai-Aerosmith readout calibration for ARTU:

Dial in the calibration number labelled on ARTU, Each ARTU has a different number.

20BJ Prepare ARTU and plummets for slant distance measurements:

1) Attach the ARM-ARTU cable to ARTU. It should already be connected to the blue box.

2) Push the preset button on the Ideal-Aerosmith readout. Check the cal ibration number on the display.

3) Extend the ARTU tape a couple of feet and let it retract. Do this severi.l times, watching haw the readout recalibrates. When the readout recalibrates accurately and consistantIy, ARTU is ready for slant distance measurements.

NOTE - The ARTU rotary dashpot is intended to slow tape retraction, but it works poorly if the tape is dirty, permitting the tape to slip over its rubber rollers. (If the tape slips badly, ARTU must be cleaned.) Therefore, it is usually necessary to manually slow down tha tape retraction, especially as the tape end reaches the ARTU body. If the tape end suddeniy is stopped, the momentum of the inner gauge block wheel (which rotates with the tape) will cause it to slip, thereby producing a calibration error. Also, the Ideal-Aerosmith kill readout often recalibrates only if the tape is retracted very slatly. The 
Ideal-Aerosmith 8000 will accurately recalibrate when the tape retracts at a normal speed.

4) Turn off the laser.

5) Remove the laser targeis from the plummets.

6) Place an optical piumet tooling ball adapter in the tooling sph?re mount on top of eash plummet. Rotate it so that the ball faces in the correct direction and sorew it down. Since the tooling ball extends to the center of the plumet's vertical axis, the exact orientation of the adapter is not important as long as ARTU's female tape end fits freely on the ball without bending the tape.

21] Take slant distance measurements (Fig. 9):

One surveyor supports ARTU on a fiducial, arcs it to get the shortest tape distance, and pushes the data irput button. The other surveyor assists by driving the cart, operating the computer, extending and retracting ARTU's tape, and calling out the readout numbers when necessary.

1) The computer is ready to accept ARTU input.

2) Push the readout's preset button.

3) Set ARTU on a fiducial.

4) Slouly pull the tape end staight out to a fiducial and slip it over the tooling ball.

5) ARTU is rolled and rotated in all directions on the tooling ball so that the readout numbers tend towards a minimum value, which is the straight-line distance between the two tooling balls.

a) Before referring to the readout numbers, it is helpful to visually orient ARTU to remove any kinks or bends in the tape at the point where it exits the ARTU jody.

b) If the readout can not be seen by the ARTU operator, the numbers must continuously be called out by the other surveyor until the input button is pushed.

6) When the minimum readout number is reached, push the input button.

7) Let the tape slowly retract.

8) Check the calibration number on the readout. If it is off by greater than $\pm .50 \mathrm{~mm}$., then:

a) Answer "yes" to the "redo measurement" query.

b) Preset the readout and push User Key 10.

c) Remeasure the distance.

If the calibration is within $\pm .50 \mathrm{~mm}$., check the input value and the slant distance error (dS).

9) Go on to the nexi measurement. 
22] Double check and finish the program:

Check that all of the input data, especially the dR's, dE's, df's, and $d S^{\prime} s$, are reasonable values before the program is continued. Once $a$ "return" is entered in rasponse to the "ALL MEASUREMEUTS ARE COMPLETE, INPUT CARRIAGE RETURN TD PROCEED" command, mistakes in the data can not be corrected unless the entire program is rerun. The foliowing summary describes the remaining program MEASURe procedure:

1) The "MEASUREMENTS ARE COMPLETE" return is entered.

2) Overla; 2 of program MEASURE is input into the computer memory.

3) Intermediate results are printed out.

4) The "output data tape" is inserted and data is uritten on it.

5) Shimming and stand orientation data are printed out by the Silent 700 .

6. Program MEASURE ends.

\section{RF Cavities - Laser Survaying}

Regians $4 B, 8 A$, and $12 A$ esch contain 12 RF cavities. Since their alignment tolerances are greater than those of the other ring magnets, they are surveyed separately, either using optical tooling or the laser system. Laser surveying proceeds in a similar manner as in the rest of the ring, with the fallowing exceptions:

A. Laser stand location:

In sectors $236(4 B), 286(8 A)$, and 300 (12A), the measured elements include cavit: number $3 A$, which lies outside of the two monuments that normally would define the limits of the sector. The inclusion of cavity number $3 A$ provides a better angle at which the first (or lasi) slant distance is taken: if the sector begins (or ends) with cavity number 38 , the slant distance to it from the monument stand is nearly perpendicular to the beam line, which causes problems in the Use of ARIU and in the data reduction.

Because of the arrangement of the cavities in these sectors, the surveyors do not have a choice of which monument to use as the "near target monument" - the laser stand must be set over the monument on the Q3-side of the sector. Only from this position can cavity number $3 A^{\prime} s$ offsets be read.

B. RF cavity roll:

on either end of the cavity is a thick aluminum clamping plate. The Talyvel level unit rests on the machined upper surface of the plate during roll readings. After lalyvel has been calibrated, a roll reading is taken from each end of the cavity. In order to see the numbers on 
the level unit, it is necessary to reverse it wran measiring the dounstream end of the cavity (the level unit's cord will be away from the aisle). The sign of this reading is reversec, and the two readings are averaged and entered into the compitier.

c. Ele.ation readings:

"One-inch" tooling balls are required for the remainder of the surveying. These tooling balls are relatively fragile, and care must bs taken when resting any heavy instrument (such as ARM or SAM) on them. since the cavity is almost entirely made of aluminum. a Gitzo tripod with a steel plate mounted on top is the attaciment point of SAM's flexible holder magnet.

D. Dffset readings:

As mentioned above, in sectors 236,266 , and 300 , cavity No. $3 A^{\prime} s$ fiducials are behind the far laser target. The target must be removed before surveying these two fiducials. It is best to check the laser buckin just before the target is removed and after it is replaced.

E. Slant distance readings:

Installation of equipment around the cavities prevents further slant distance measurements from being taken in the normal manner. However, since the alignment tolerance in the direction of the beam is relatively large, the initial placement of the cavities is sufficiently accurate. 


\section{EQUIPMENT}

I. Fixtures

PEP Survey and Alignment uses four types of ring magnet fiducial fixtures. Each accurately places one or two reference tooling balls near the magnet surface, from which measurements of magnet elevation, offset, and location along the beam line sre taken. Quadrupole and sextupole roll measurements are taken using large U-shaped fixtures that i $i t$ over the magnets. Injection $i$ ine magnets and some ring elements are machined to accept a special "l inch" tooling ball as a reference paint.

\section{A. Bend magnet fixture (Fig. II):}

The bend magnet fixture incorporates a calibrated digital-readout micrometer, the tip of which acts as one of the three contact points that rest against the vertical aisie-side of the magnet. A number stamped on the top surface of the bend magnet above the fiducial is dialed into the micrometer. This number is derived from magnetic measurements, and it represents a corraction in the roll to be given the bend magnet to compensate for its sag in the middle and at both ends. The other two contact points are $1 / 2$ inch tooling balls. They seat in a horizontal $v$-shaped groove in the laminations, which is accessed through slatted plugs welded into cutrouts in the magnet's iron cover plate. The sides of the groove determine the $x$ and $y$ position of the fixture. z-location is determined by the sides of the plug's slot. The third point, the micrometer foot, is below the tooling balls, and rests against a flat surface on the laminations. The micrometer ler.yth cetermines the roll of the fixture.

Proper emplacement of the bend magnet fixture is critical. Improper attachment of the fixture will cause inaccurate readings and also create the possibility that the fixture may fall off the magnet during measurements, causing damage to the fixture and to the instrument resting upon it. The following procedure is a reliabie method of mounting the bend magnet fixture:

1) Unlock the micrometer locking screw. Preset the micrometer readout to the number stamped and written above the fiducial on top of the magnet. Lock the micrometer locking screw.

2) Clean any excess paint or dirt from the surface of the iron to which the fixture's magnet will be attached.

3) Switch the fixture's magnet on - move the lever up and over the front of the magnet.

4) Pull the black plastic permanent magnet slide out towards the aisle.

5) Grasp the fixture in both hands, with the last three fingers on each hand inside the raised portion of the frame. The thumbs are held on the aisle-side of the permanent magnet. 
6) Place the fixture against the bend magnet. The two tooling ball feet must each touch the upper and lower surfaces of the groove in the laminations.

7) Press straight forward on the permanent magnet until it oficks into place against the iron cover plate. The space between the permanent magnet and the frame should be equal on all sides and the fixture's compression springs should be perpendicular to the frame. If the permanent magnet is too high or low or pitched to one side, the tooling balis nay lift out of the groove, or the fixture may bi: easily knocked off of the magnet.

8) Slightly tuist the fixture to check that it is completely seated and securely attached.

9) Push in the magnet slide until resistance is felt. The usdging effect of the slide prevents the fixture's tooling balls from sliding down in the groove when weight is put on the fiducial ball during measurements.

Dataching the fixture:

1) Grasp the fixture as previously described.

2) While pushing in on the permanent magnet with one thumb, pull the magnet switch lever down with the other, turning it off.

3) Slowly let the magnet spring back to its unlaaded position off the iron surface.

Bend magnet fixture calibration:

The bend magnet fixture must be recalibrated after any damage to it due to dropping or shocks to the micrometer. It is also a good idea to check the calibration after a few months of use. The fixture is calibrated by attaching it to the iron calibration knee, setting the micrometer to make the fixture roll pad parallel to the knee's roll surface, and then adjusting the micrometer counter to read $00.00 \mathrm{~mm}$. The following procedure is a modification of the instructions given on drawing QT-201-130-24-80-E:

1) Set up calibration knee, bend fixture, and Talyve ?:

a) Set the knee on a flat stable surface. The surface need not be perfectiy level. A wooden bench top will suffice.

b) clean all contact surfaces on the knee, including the entire upper surface, the tooling ball v-groove, and the micrometer pad.

c) clean the fixture's Talyvel level unit pad.

d) Set the fixture micrometer to $00.00 \mathrm{~min}$.

e) Attach the fixture to the knee, making sure that the tooling balis contact the upper and lower surfaces of the v-groove.

f) Calibrate Talyvel. Set the leveling knobs to $u$.

g) With Talyvel set to the $100 \mathrm{sec}$. scale, measure the knee's transverse roll - parallel to the fixture mounting surface. The roll srocld be within \pm .0001 in/in (or $.1 \mathrm{~mm} / \mathrm{M}$ or 
20 sec.). If not, rotate the knee until the transverse ral! is in tolerance.

2) Adjust the knee and fixture roll to the same value:

2) To measure the kree's longitudinal roll, set the level unit on the knee parallel to the fixture's level unit pad. placa the level unit in the same place each time the roll is measured. Since the level unit is not to be reversed during this procedure, the knee's roll should be iaken with the level unit cord extending to the fixture-side of the knee, so that when the level unit is placed on the fixture, the cord will noc interfere with the fixture body.

b) Rather than nemorizing the roll of the calibration knee, it is simpler to turn one leveling knob to null the meter - to canter the needle at 0 . Thus, with the level unit on the fixture, the meter will read within one marked division of 0 when the fixture roll is sufficientiy close to that of the knee.

NOIE - The resolution of the Talyvel meter is one marked division, which is $0.02 \mathrm{mrad}$ on the $100 \mathrm{sec}$. scale. A $0.01 \mathrm{~mm}$ change of the bend fixture micrometer is equivalent to a change of $0.04 \mathrm{mrad}$ in the roll of the ievel unit pad. Since in this procedure the miciometer is to bo calibrated to $\pm 0.005 \mathrm{~mm}$ (one-half of a counter digit, or $\pm 0.02 \mathrm{mrad}$ ), the Taivvel meter on the $100 \mathrm{sec}$. scale has sufficient resolution to compare and adjust the rolls of the knee and the fixture.

c) Place the level unit on the fixture.

d) Adjust the micrometer to null the meter. Make sure that the tooling balls are contacting the v-gruove after the micrometer has been adjusted. If either ball has "walked off" one of the surfaces, remove the level unit and the fixture and reinstall both items.

e) Repeat steps a-d until the roll of the knee and the fixture bath register 0 .

f) Check the micrameter digital readout. If it reads within $.005 \mathrm{~mm}$ (one-half of a counter digit) of $00.00 \mathrm{~mm}$, it needs no further calibration. Dtherwise, lock the spindle lock, recheck the roll, and continue on.

3) Adjust micrometer:

a) Remove the fixture and place it on its side, with the micrometer counter facing up.

b) Remove the two screus holding the lens and lens frane onto the micrometer. Remove the lens and frame, exposing the digital counter unit and its two hold-down screws.

c) Loosen the digital counter screw and slide the counter away from the spindle lock until its gears disengase the micrometer gears. The counter gears arid wheels can now be turned freely with a small screwdriver.

d) Turn the counter wheels until they read $06,00 \mathrm{~mm}$. 
e) Slide the counter unit back into position to reengage its gears. Tighten the two screws. Adjust the position of the counter to both minimize backlash and prevent binding as the spindle is turned. Measure backlash by loosening the spindle lock and holding down the counter wheels with a finger while turiing the micrometer spindle. The spindle's usual minum backlash (free play) is a large fraction (up to $\pm .005 \mathrm{~mm}$ ) of a scribed unit on the spindie.

4) Recheck fixture calibration:

a) Leave the lens and frame off.

b) Remount the fixture on the knee.

c) Repeat procedures 2 and 3 until the counter reads within $\pm .005 \mathrm{~mm}$ of $00.00 \mathrm{~mm}$ when the fixture and knee rolls are the same. Generally, one careful iteration is sufficient to achieve this tolerance.

d) Remov? the fixture and attach the counter lens and frame. Mark the calibration date on the fixture.

Check bend magnet fixture dimensions:

1) The distance betueen the outer edges of the fiducial ball and the magnet mounting ball is 2.500 in.

2) Attach the fixture to the calibration knee. The horizontal distance from the outer edse of the fiducial ball to the mounting surface is 2.354 in.

B. Quadrupole magnet fixture (Fig. 12):

This fixture has two fiducial balls from which measurements are taken. It is mounted against the aisle-side of the quadrupole using the same compression spring and switchable magnet arrangement as in the bend magnet fixture. Three spherical butions contact the vertical laminations to give a location in $x$ (offset). A hardened stainless steel shoe on the bottom edge of the $f i x t u r e$ rests against the horizontal surface of the magnet ears to provide a $y$-reference (elevation). The fixture is located in $z$ by a hole in a welded plate just above the exposed vertical iaminations into which fits a tooling ball attached to a vertically-moving slide on the fixture. The free travel of the tooling ball prevents it from constraining the fixture in its vertical positioning. Use the following procedure to attach the quadrupole fixture:

1) Remove the quad ear clamps it they interfere with the fixture. visually check that there is no contact once the fixture is in place.

2) Clean all contact surfaces on the laminations of rust, metal paricles, tape, dirt, or paint.

3) Switch on the permanent magnet,

4) Loosen the vertical loading screw. 
5) Place the fixture on the magnet, seating it well,

6) Press in on the permanent magnet until it contacts the laninations.

7) Tighten the vertical loading screw until the tongue is pressing tightly up against the magnet's weld relief groove. This ensures that the fixture firmiy contacts the ears below.

8) Check that:

a) The bottom plate contacts the ears along its entire length.

b) All threo spherical buttons contact the laminations (use a flash! ight).

c) The verticaliy-maving slide has some free play. If not, then one of the following probiems exists:

1) The hole in the welded plate is too high or low on the magnet for the slide's travel. A hole at the correct height must be drilled.

2) The hole is tco small or shallow causing the tooling ball to bind or bottom out. The hole must be enlarged or deepened.

3) The welded plate protrudes excessively into the aisle and the aisle and contacts the movable slide. A shallow large diameter hole accomodating the slide must be reamed into the welded plate, eliminating contact.

Since the quad fiducials are close together, any errors in fixture attachment will be greatly magnified during the final computation of magnet orientation and strut changes. For instance, a .010" space between one of the buttons and the laminations might cause a .240" error in the length of the horizontal strut.

Check quadrupale fixture dimensions:

1) Mount the fixture on the leveled bend magnet fixture calibration knee (remove parts as necessary).

2) The vertical distance from the bottom of the stainless steel shoe to the top surface of the fiducial ball is 3.991 in.

3) The horizontal distance from the mounting surface on which the spherical buttons rest to the outer edge of the fiducial ball is 2.280 in.

c. Sextupole magnet fixture (fig. 13):

Two spherical buttons rest on the sextupole ear clamps to locate the fixture in $y$, and three buttons seat against the sloping aisle-side of the magnet to provide an $x$-reference, $z$-location was not fixed on the magnet during the early surveying of PEP, but the fixtures have since been modified to provide a fixed z-location by the addition of a dowel pin that locates off of one end of the sextupole. There are separate $f$ ixtures for use on the three sextupole types. check for 
proper contact between the fixture and the sextupole after the permanant magnet has been seated against the laminations.

Check the sextupole fixture dimensions:

1) Mount the fixture on the leveled bend magnet fixture calibration knee.

2) The horizontal distance from the mounting surface to the outer edge of the fiducial ball is 4.288 in.

3) Set the knee and fixture on a sin-bar adjusted to an angle of 30 degrees.

4) The vertical distance from the bottom of the spherical buttons to the top of the fiducial ball is 3.562 in.

\section{Insertion quadrupole fixture:}

An upstream (right-handed) and a downstream (left-handed) insertion quadrupole fixture are attached at the ends of the magnet. Three spherical buttons rest against the vertical aislerside laminations to locate the fixture in $x$. A thin shim clamped horizontally to the bottom of the fixture slides into the magnet's split plane to provide a location in $y$. (If the shim does not slide smoothly into the split piane groove, it should be replaced by the next smaller size shim.) A pin on the fixture butts up against a plate near the end of the magnet for z-positioning. If the magnet coil's sheet metal cover is installed upside down, the access hole for the pin will not be aligned. The cover must then be removed and reinstalled.

The tolerances to which the insertion quadrupoles must be aligned are the most strict of any element in the ring. Therefore, careful placement of the fixtures is essential. It is most important to check that all three buttons are set against the laminations. Use a flashlight and a very thin feeler gauge to make sure that there is no space between the magnet and the buttons.

Check insertion quadrupole fixture dimensions:

1) Remove the shim from the shim clamp and mount the fixture on the leveled oalibration knee.

2) The horizontal distance from the mounting surface to the outer edge of the fiducial ball is $2.253 \mathrm{in}$.

3) Reinstali the shim.

4) The vertical distance from the center of the shim to the top the top of the fiducial ball is $5.368 \mathrm{in}$. 
E. Quadrupole and sextupole roll fixtures (Figs, 2 and 3 ):

Two buttons on the battom of one of the fixture jegs rest upon the ears on one side of the miagnet and a third button sits on the ear on the opposite side of the nagnet, with the fixture arching over the magnet in between. The Talyvel level unit clamps to the top of the fixture. Care must be taken that the magnet ears are free from dirt and that water lines or cables do not interfere with the fixture installation.

F. Dne inch tooling balls:

A specially made tooling ball is used in the surveying of RF cavities, wigglers, low field bend magnets, and all injection line magnets. The center of the $1 / 2$ inch diameter ball is one inch from the magnet contact surface. The neck of the ball allows for a greater degree of movement of the tooling scales or other surveying equipment than does a normal tooling ball.

The tooling balls should periodically be checked for accuracy of the one-inch dimension. The cylindrical base is a press $f i t$, and on those balis where this part hasn't been pinned to the ball's shaft. slippage may occur. Also, the welded ball-shaft joint receives considerable stress during $r$ cavitiy surveying when SAM and ARM rest upon it. A few of the balls have failed at that spot, and care is required to protect the instruments from falling.

[I. Tunnel Monuments (Fig. 14)

Into the PEP ring floor have been cast 102 iron monument wells. NIT and SIT each contain 12 monuinents, and there are sixteen brass plugs in the junction area. Installed in each well is a monument pin, which is a surveying reference point. Periodically, the Hell, pin, and associated hardware should be cleaned of debris, rust and water.

A. Installation of the monument pin:

The following procedure is from PEP drawing AO-201-123-DO-RO-E:

1) Loose assembly:

a) Place the pin oup in the center of the well.

b) Remove the pin's protective plastic cover and place the pin in the pin cup. The stainless steel pin has a spherical base so that it can be rotated to a plumb position while being clamped doun.

c) Place the pin clamp plate over the pin.

d) Place the triangular clamp ring on the pin clamp plate. 
e) Thread 3 hex head cap screws through the clanp ring into the bot:om of the wall. Thread the screus tre sams number of turns intil they are finger-tight against the ring.

2) Leveling and tightening:

a) Fit the pin alignment fixture over the $p$ in and insert the pin alignment rod into the pin.

b) Using the rod as a lever, rock the pin to center the alignment fixture's bubble. The pin is now vertical.

c) With a torque wrench, slightly tighten each cap screw, noving from one to another until $150-1751$ bs. of tarque is reached. The bubble will drift away from the screw being tightened. only if the torque is increased on each screw by smail increments can the bubble can be centered with proper torque on each screw.

3) Orilling:

a) Drilling prepares the monument for permanent lacking of the pin's positicn.

b) Using the hole in the pin as a guide, drill into the iron base of the monument with a No. $6(.204 ")$ bit until an indentation the diameter of the bit has been made.

4) Locking the pin in place:

a) lnstall a set screw in the pin's hole and tighten it against the indentation in the bottom of the well.

b) Install a second set scres tight against the first.

c) Bolt down the monument lid and o-ring with four hex-head screws.

\section{B. Monument c.leaning:}

The menument's stainless steel pin is the only piece of hardware that must be clean during surveying. Slight amounts of dirt, rust, or water in the well will not affect the use of the pin as a referense point. However, if the well has filled up with water and cebris, it is necessary to clean and dry the hell, tap out the montment if screw holes, and replace the ouring if it is in poor candition. This will ensure that the well can be properly sealed after surveying to protect against further contamination.

1) Remove all water from the well using a wet vac or a blow bulb.

2) Scrape off losse dirt and rust from the interior of the well, especially from the o-ring mating surfaces. Be very careful that the pin is protected from any nicks, scratches, or banging from the cleaning process. A great amount of time and effort is required to replace and resurvey a damaged or moved pin.

3) Use an electric drill with a coarse wire brush to smooth the smooth the o-ring mating surfaces. Other tools such as carbide scrapers may be used as needed.

4) Orill out the compacted dirt from the monument lidscrew holes with a 1/4" masonry bit. Vacuum up the loosened chips and dirt. 
5) Tap the screw holes with a $3 / 8^{H}$ N.C. bottoming tap. Use tapping oil. Remove tap and dirt frequently.

6) Spray the weli, screw holes, and lid with a jubricant such as WO -40 .

7) Replace the o-ring if it is caked with rust and dirt which might prevent a water-tight seal. Lightly grease the o-ring and the iron mating surfaces.

8) Replace corroded or missing bolts with stainless sieel bolts. Tighten down the monument lid.

IIs. Liquid Level System (Fig. 15)

The liquid level system provides the elevation references for the vertical alignment of the elements in the PEP ring. The system consists of 110 liquid level wells in the arcs and interaction region halls interconnected by valve-controlled unpressurized air and water lines. The walls are glass containers partially filled with water. The height of the ton of the well relative to the surface of the water can be measured (or "read") by a depth nicrometer in the top of the well. A tooling ball mounted on top of the micrometer provides the reference fiducial for elevation measurements.

Twice yearly, the wells are calibrated to determine the amount of settling in the PEP ring. Just before the calibration, all of the water and air values are opened to permit free flow throughout the system. The height of the water in each well then adjusts to a single gravitational equipotential surface. In other words, the water is at the same elevation, in an ellipsoidal coordinate system. Also. the air pressure in the system equilibrates, eliminating water level changes due to local variations in the air pressure. Since temperature changes cause the water level of the system to drift, simultaneous water level measurements are taken at a master well and at some other well in the ring to give the difference in elevation. Each well is read in turn, and the data are used to compute the amuunt of settling in the $r i n g$ relative to the last calibration. If the entire PEP ring is to be resurveyed, all of the micrometers are changed to new calculated settings so that the micrometer tooling balls are at the same ellipsoidal elevation, the "master elevation", which is the average height of the uells in the tunnelled regions of PEP - those areas least likely to have had a change in elevation due to movement of the earth. Later on, during surveying, the computer program MEASURE will compensate for the deviation of the wells' tooling balls, which are on an ellipsoidal surface, from the flat plane in which the magnets are to be aligned.

The resolution of the liquid level wells, fixed by the micrometer's digital readout, is $\pm .01 \mathrm{~mm}$., but systematic errors limit the accuracy to about $\pm .10 \mathrm{~m}$. Over the large distances encountered in the ring, the 
liquid leyel makes it possible to measure slopes as small as $\pm 2 E-7$ radians $( \pm, 20 \mathrm{~mm}$. in $1000 \mathrm{M}$.).

\section{A. Lisuid level sssiem hardware and installation:}

In each of PEP's six arcs are iocated 17 Hells. aird tic wells have been installed in IR halls 2, 4, 8, and 12. Four-way one-inch water valves, witich control flow through the copper pipe, are located in regions $2 \mathrm{~A}, 2 \mathrm{~B}, 4 \mathrm{~B}, 6 \mathrm{~A}, 6 \mathrm{~B}, 8 \mathrm{~B}$, and 12B. Four-day air line valves are lacated in regions $29,43,85$, and $12 B$. The air and water ilnes ars discontinuous at $r \cdot i g$ ion 6 .

1) Liquid level well assembly: The following well assembly procedure is from drawing AO-201-125-00-R1-0:

a) Micrometer top assembly: The micrometer unit is a modified digital depth micrometer. Its standard rod has becn replaced by a pointed stainless steel probe and a tooling ball hasbeen mounted on its upper end (see drawing AO-2D1-125-20-R1-E).

i) Install a spring-loaded teflon seal in the steel well top lusing the seal tool and bushing.

2) slide the micrometer through the hole in the seal and seat it in the top of the well.

3) Install a brass-tipped socket-head set screw in each of two locations in the well top and tighten them against the micrometer.

4) Against the first pair of set screws install two cuppoint sei screws, locking them tight.

b) coat a feu threads of a brass union coupling with Loctite 277 high strength adhesive sealant and screw it into the base of the well. Use only moderate torque to tighten the fitting.

c) Sp:ay six button-head cap screws and the tapped holes on both ends of ihree tie rods with Loctite Primer $N$ or $T$.

d) l'se Loctite 277 on three of the screws and screw them into the tie rods.

e) Clean the well base, top, glass housing, and inicrometer tip with alcohol.

f) Insert the three tie rods through the base and place the base on a flat surface, rods pointing up.

g) Place a rubber gasket, the glass housing, and a sacond gasket inside the tie rads.

h) Place the well top assembiy on the rod ends so that the air line itting is on the same side as the water line fitting.

i) Install the remaining three screws in the rods. Tighten the screws while keeping the glass centered on the gaskets.

2) Yell installation in the ring: The following procedure is

from orswing $A D-201-125-32-R O-E$ :

a) install well floor mount: 
1) The floor mount is usually located near the end of a raft ciosest to a monument. The liquid level rod, when in use, must have clearance to be mounted plumb and unobstructed along the line of sight at the elevation of its laser target. The aisie-side of the floor maunt is located 3. 25" into the aisle from the side of the horizontal aluminum cover on the bend magnet under which the weil is vlaced.

2) On the concrete floor, mark the location of the two mounting holes and remove the floor mount.

3) Use a Hilti TE 1/2-6 drill to drill two holes to a depth such that the top of the Hilti drop-in anchor will be $0.0-0.1$ " below the surface of the floor. Remove dust and cenent particles from the holes.

4) Insert a drop-in anchor. If the hole is too deep, add a fen concrete chips to the hole.

5) Place the special setting tool in the anchor and pound the top of the tool with a small sledge hammer until the enlarged portion of the tool butts up against the anchor. The anchar is now seated.

6) Install the floor mount using two hex-head screws and washers. The screws should be tightened until the washers warp upward.

b) Install the floor bracket on the floor mount:

i) The bracket is located so that the micrometer tooling ball will be $q^{\prime \prime}$ inta the aisle from the side of the aluminum cover on the bend magnet. Use a plumb bob to check this dimension.

2) Four screks and Unistrut nuts and springs hold the bracket to the floor mount. Tighten the screws until the washers warp upward.

c) Install the well on the floor bracket:

1) Attach 1/4" I.D. Tygon air line to the top of the well. Tighten the coupling somewhat more than finger-tight.

2) Place a u-bolt on the well.

3) Insert the u-bolt ends through the bracket, a clamp stiffener, and washers and tighten this assembly with two nuts behind the stiffener. At this time, the well is not leveled or placed at the proper elevation, so the u-bolt is tightened just enough to temporarily secure the well.

4) Insert a nut and nipple assembly into $3 / 8^{\prime \prime}$ I. B. Tygon water line and fasten it with a spring-type hose clamp.

5) Place a union gasket over the Hell's male union coupling and screw on the water line nut.

6) Add a nulon quick-disconnect fitting to the Tygon air line about 12" from the well. Attach the Tygon tubing to the copper air line connector.

7) Attach the Tygon water line to the hose connector on the copper water line's ball valve. Fasten it with a springtype hose clamp. 
d) Place a protective plexiglass cover over the well and secure it with a cable crimped with a Nico-Press stop sleeve.

B. Liquid level calibration:

1) Preparation: The preparation of the liquid level system may take one or more days prior to calibration, depending on the condition of the wells and copper lines. For calibration to be meaningful, all water leaks in the $j "$ copper water line joints, the Tygon tubing, and in the wells and couplings must be sealed, the copper and Tygon air lines must be dry and unbroken, air must be removed from the water lines, the wells must be filled to the proper level, each micrometer must be functional, the micrometer tip and water surface must be clean, and newly installed wells should be leveled at the correct height. Careful preparation is crucial since the results of the calibration will rot always clearly indicate defects in the system. In the liquid level iog book, record all damage and repairs to the system, valves opened and closed, other procedures involved in the preparation of the welis, calibration readings taken, and calculations.

a) Inspect liquid level hardware for damage: since the previous calibration left all of the wells properly filled, their valves shut of $f$, and their Tygon lines in working order, any deviation from these conditions found upon inspection of the system are a result of either subsequent damage or deterioration of the hardware or a chronic slow leak which may be difficult to find. 1) Each well is inspected for:

a) Damage to the kell or mounting hardware: The well and mounting hardware should show no signs of damage from being struck by equipment or people moving through the tunnel. The screws should all be tight and the entire assembly should feel very solid. Note any evidence that the well position has been changed since the last the last calibration.

b) Smoothly turning micrometer: In some locations, rust or residue from ceiling seepage may jam the micrometer mechanism. If this is the case, the well must be replaced.

c) Proper water level: If the well is dry or nearly so, most likely the Hell's male water line coupling has a leak, either at the gasket or where it screws into the base. Test for a current leak by feeling underneath the coupling for water. Also look for a rupture in the Tygon water line. If the well is overfull, there may there may be water in the Tygon tubing air line and possibly in the copper air line as well (see the next section). 
d) Clean water surface and micrometer tip: If either the water or the micrometer has a significant amount of residue on it, the interior of the well will have to be cleaned.

2) Inspect water and air lines for:

a) Leaks in the copper water line: A slow leak may creata a small puddle on the floor. The exact location of a leak is faund by checking the underside of the pipe for water. The entire length of the pipe, inciuding sections behind the rafts, must be at least visually inspected. Most leaks are due to poorly soldered joints, which must be repaired.

b) Breaks in the copper air line: Dccasional small air leaks in the copper air line are not significant, but large breaks in the pipe must be repaired.

c) Condition of the Tygon water line: Air in the water line usually indicates a leak in the hell couplings or, less frequently, a hole in the tubing itself. If the outer surface of the Tygon is dirty, air bubbles can be seen most easily by lifting various parts of the tubing and watching for bubble movement. If the well's ball valve is closed (as it should be), the air probably hasn't entered the copper line. The Tygon line should be free from kinks, and no cables or other equipment should be resting on it. Greyish algae may have grown in the tubing, and it should be flushed out, or the Tygon replaced.

d) Condition of the Tygon air line: Water in the Tygon air line can be detected by raising the tubing and watching for water movement, or, in more extreme cases, air bubbles in the water. Even a shori continuous section of water in the air line will effectively block the air circulation necessary for proper calibration, so the air line must be inspected carefully. Water in the air line most likely has entered from an overfilled well, but it may have entered from the copper line instead. Therefore, if there is water in the Tygon tubing, the copper line may be partially filled also. This can be checked by detaching the quick-disconnect fitting or cutting the Tygon tubing near the copper line connector, lowering the copper air line by sliding it down in its brackets, and seeing if any water pours out. If there is water in the air ine, note it down and repair it later.

3) Check and adjust valves:

a) The wells' ball vaives should be closed: The stem and handle are parallel to the main copper line (perpendicular to the Tygon (ine).

b) The air line valves are closed side to side: The handles of the four copper air line valves are parallel to the line, with the pointer, which marks OFF, in in either direction. 
c) The $i$ " water line valves are open side to side: $T$. stamped CLOSE on vie corner of the valve is perpendicular to the copper line and faces either the plain face of the valye body or a solid plug. The valye is now open from ane side of the line to the other and closed to the outside.

b) Make repairs as needed:

1) solder the leaking copper line joints.

2) Replace any damaged wells: With a pen draw a line on the bracket across the top of the oid well before moving it. Replace the well with a new one and tighten it down at the same elevation on the bracket using a bullseye bubble level to keep the well level. Attach the Tygon lines to the new well.

3) Replace damaged Tygon tubing.

4) Repair leaking well couplings: Unscrew the Tygon water line from the well coupling, unscrew the coupling from the base, clean and recoat the coupling threads with Loctite 277 and reassemble. Make sure that the fitting has a gasket.

5) Remove water from the Tygon and copper air lines:

a) Try to determine and remedy the cause of the water in the line. It may have come from a neighboring well that was overfilled, in which case a large section of copper line may be flooded.

b) Remove the Tygon tubing from the copper air line and detach the quick disconnect.

c) Blow out the Tygon tubing.

d) Lower the copper air line and see if water drains out. If so, adjust the height of the air line so that it is continuously sloping from a low point at the well to a high point midway between the well and each neighboring well. similarly check the neighboring sectors for water is the air line. Once all of the water has been drained, leave the air line as it is. Reattach the Tygon tubing.

6) Remove air from the Tygon and copper water lines (flush the system): Large amounts of air will usually be found in the Tygon water line connected to a leaky, dry well. It may also enter through a break in the tubing. Bubbles over 1/4" in diameter should be removed from the tubing when the wells are filled. Air will not enter the copper water line uniess it is being filled improperly, through a major leak in a joint, or unless a vaive to a leaking well is left open, causing water to drain from the main line. To remove air from the copper line, a pump is used to flush the system at high water volume rates. Air is removed from the Tygon when the wells are filled (see the next section). To flush the system: a) Set the four stainless steel 50 gallon drums near the in valve to the left of the proton alcove in region $12 B$. 
Arrange the drums and the pump in the following order, from right to leit: the pump is to the left of the valve, then the drum with the valve shutaff (with the shutoff on the pump-side), then two drums with two $2^{n}$ openings, and finally the fourth drum, witl one 2 " opening.

b) Interconnect the drums, pump, and valve with $2^{\text {th and }} 1$ " hoses, adapters, and gaskets. Tighten the connections with a large pipe wrench. The pump is connected to a junction box using a special card that has a 3-prong femaie end and a 5-prong male end, to convert from 3-phase $20 \mathrm{~s}$ volts to single phase.

c) Attach the garden hose fire hydrant adapter to the hydrant outside of region 12 and tighten it with the special tool. Attach the garden hose to the adapter.

d) Renove the two scren caps from the top of each drum.

e) Fill the drums with water from the garden hose and add the appropriate amount of algicide. Keep the drums full during the flushing of the system.

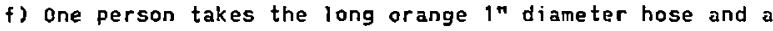
gasket to the first alve beyond the section of copper line that is to be flushed. Usually, the valve in $6 A$ or $6 B$ is used. The hose is attached to the valve and stretched to a drainage gutter or into a nearby tunnel access.

g) All of the Tygon air line quick-disconnects are detached in the section of the line to be flushed.

h) At a pre-set time, the far valve is opened to the outside and to the pump-side of the copper line. The valve should be closed to the other side of the water line. simultaneously, the drum and pump valves are opened, the water line valve is opened to the pump and to the farvalve side (closed to the other), and the pump is turned on. It will take a fen moments for water to begin streaming from the far valve hose.

i) Wait several minutes until the water has been completely changed and all of the air in the line has been flushed out. Stop the pump and close the valyes at the pump.

j) The far valve is shut off as soon as the flow of water starts to slow. Both valves are now open side to side but are shut off to the outside.

k) Flush the other half of the ring in the same way.

1) Connect the fourth barrel to the main valve. Using the pump, fill the barrel with the remaining water. It will be used to fill the wells.

c) Fill the wells:

1) Detach all of the Tygan air line quick-disconnects.

2) check that all well valves are closed.

3) Open the main water valves side to side, if this hasn't been done al ready. 
4) Prepare the 50 gallon drum (if not previously prepared when the system was flushed):

a) Attach the orum with one 2" opening to the 1" valve in region $12 \mathrm{~B}$ using the brass adapter and the long orange hose.

b) Attach an adapter and a garden hose to the fire hydrant outside of region 12 .

c) Fill the drum with water and the correct amount of algicide.

5) Fill the wells:

a) Dpen the main valve at 128 to the drum and to the water line on both sides of the valve.

b) Open each well valve and fill the well to the height of the micrometer tip when the micrometer reads $12.50 \mathrm{~mm}$. (about one-third full). Two people are needed for this task; one opens and closes the valve while the other watches the water level in the well.

c) Welis and Tygon water lines that are dry or that need to have dirt flushed out of them require a slightly different procedure: One person unscrews the Tygon water line from the well and the other turns on the valve and water flows through the tubing until all of the air has been flushed out. The well is partially filled and drained several times to remove dirt and while the water is running, and the Tygon line is reattached to the well. The well valve is shut off when the water is at the correct height. The tubing is squeezed several times to force any remaining air out of the couplings.

d) close the main valve at the drum. The valve is open side to side.

2) Take calibration readings:

The procedures described above may be done the day before the calibration readings are taken. To prevent contamination, the air line quick-disconnects should not be left detached longer than one night, depending on conditions in the tunnel. Calibration readings arz taken with the well valves open. The air line is open to the atmosphere in only one place.

a) Check the system and open the valves:

1) Check all wells for proper water level, leaks, water in the air line, etc. Repair as necessary.

2) Disconnect and drain the drum.

3) Open the well valves - the handle is parallel to the Tygon water line. The water level in the first few wells may change drastically as the valves are opened. This is caused by an adjustment of the copper water line due to temperature changes since the time the wells were filled. For instance, the copper tubing may be constricted, causing the water in the first one or two wells to be nearly completely drained as the pipe readjusts. Shut the valves off before the wells go dry and open several more wells to relieve the negative 
pressure. The water level may oscillate for a period of time, causing some wells to overfill. As more wells are opened, the kater level will stabilize at an average height.

4) After all well valves have been opened, reattach the quickdisconnects.

5) Check that the main air and water line valves are open side to side. (If the wells in only half the ring are to be calibrated (in which case the valve in region $12 \mathrm{~B}$ wauld be closed side to sidel, well 201 in region 1 must be calibrated with the wells in region 11 since the 128 valve separates it from rest of region i.) one air line valve is opened to the outside and to both sides of the line. The vaive at region $12 B$ is usually used for this purpose. The air line should be sealed from the atmosphere in the rest of the liquid level system.

b) Final preparations and calibration readings:

For each well in the ring a reading is taken at

trie same tine as a master well reading is recorded. The entire set of readings takes a continuous period of about 140 minutes.

1) The equipinent required by each of the two surveyors consists of a watch with a seconds display, a flashlight, and a notebook and pen. The liquid level log book, which the master well reader will use, is laid out in table form with the column headings TIME, MASTER WELL READING, OTHER WELL READING, and OIHER WELL NUPBER. The master well reader uses the first two columns. The other surveyor may take a small notebook in which will be recorded the time of the reading, the well number, and the reading.

2) The choice of master well is somewhat arbitrary. one surveyor is stationed at this well during the entire calibration period.

3) Both survevors synchronize their watches to \pm 5 seconds.

4) The master well reader takes readings for a few minutes to check the stability of the water level. To take a reading: a) Raise the micrometer tip from the water.

b) On the initial reading, try to siake off any condensed water drops that might fall into the well during a reading. If water does drip, Hait a minute for the water level to stabilize before taking the first reading.

c) As the time approaches the minute mark, slowly lower the micrometer until the tip just touches the water surface. Depending on whether the water and micrometer tip are contaminated with oil or other substances, the water will either suddenly form an upward concave meniscus on the micrometer tip as soon as the tip touches, or the tip may slightly indent the water surface. The upward meniscus is easily detected since it refracts the light and images transmitted through the water. If the tip indents the water, it is difficult to see the contact point, so use a flashlight to illuminate the water surface. 
d) If possible, back off the micrometer and take another reading within a few seconds of the minute mark.

e) check the readings for stability: they should not change by more than \pm .01 to $.02 \mathrm{~mm}$. per minute. The readings change due to several factors; the water temperature fluctuates, small leaks occur in the system, etc. Over the course of the calibration, the usual rate of water level change is about $.20 \mathrm{~mm}$. per hour.

5) Take microineter readings:

a) Every minute on the minute the master well is read in the manner described above. The time and micrometer reading are writien in the log book.

b) At the same time, each of the other wells are read on the rinute. The well number, time, and the reading are recorded. Usually one well can be read each minute, but it is not necessary to do so, especialiy in the interaction region halls, where it is sometimes difficult to gain access to the uells. (since the wells in the i.r. halls are unnumbered, they are labeled by combining the region number with the side of the hall that they occupy ("A" or "B"): for example, wells $4 A$ and 48. )

c) Usually, one surveyor takes the master well readings until the other has made a complete circuit, returning to the master well. If only a part of the ring is to be calibrated, the master well is read until the other surveyor has returned after finishing his readings. This will result in a few extra master well readings that were taken during the other surveyor's walk back.

d) After the well readings have been finished, copy the readings from the other wells on to the appropriate minute line in the log book, next to the master well readings.

e) Leave the valves open until the neu liquid level settings have been calculated (if a micrometer reading or recording error is found in the data reduction. the wells in question can quickly be reread).

3) Calculate new liquid level settings:

a) Theory and data reduction:

Since the water in all of the wells stabilizes at the same ellipsoidal elevation, the difference between the master iell and other well readings, defined as delta = other well reading master well reading, is simply the difference in elevation of the two well assemblies, not of the water level at each well. For instanct, well 290 may have been installed $3.00 \mathrm{~mm}$. lower than master well 224, in which case, during cal ibration, if well $224 \mathrm{had}$ read $10.35 \mathrm{~mm}$., the reading at well 290 would be 13.35 (delta $=3.00 \mathrm{~mm}$. ). Well 290 has a higher number even though the well is lower because the micrometer must be extended out of the well body farther to reach the same elevation as the micrometer in well 224 . (The micrometer reads $0.00 \mathrm{~mm}$. when contracted and $25.00 \mathrm{~mm}$. When fully extended.) The absolute 
reading of a micrometer is of no importance since it is simply a function of low much water has been added to the system; only the difference, delta, has significance. For example, if more water had been added to the wells, the master well may have read $12.01 \mathrm{~mm}$. and well $29015.01 \mathrm{~mm}$., but the difference in elevation, $3.00 \mathrm{~mm}$, would be the same.

To simplify the following explanation, let us assume that well 224 is the absolute elevation standard, in other words, we have confidence that it has not changed in elevation since the last calibration. Its previous setting, the "master setting", would then be the master elevation to which all of the wells in the ring are ta be set. Since the master well's micrometer and another well's micrometer are at the same elevation when there is the difference delta between their readings, if we change the master well reading from the water level reading to the master setting, and also adjust the other well micrometer reading so that delta is the correct value, the two micrometer tooling balls are at the same height - the master elevation.

Therefore, to calculate the other well's setting where its tooling ball is the desired height, simply add delta to the master setting. Thus, the new setting $=$ cmaster setting + (other well reading - master well reading)s. For example, if well $224^{\prime} \mathrm{s}$ master setting is $9.11 \mathrm{~mm}$, and delta for well 290 is $3.00 \mathrm{~mm}$., then the new setting for well 290 is $12.11 \mathrm{~mm}$.

Well readings in the stable tunneled portions of the $r$ ing such as Region 9 are used to calculate the master elevation, the unchanging reference elevation. For wells 275-285, the average change in elevation from the last calibration is calculated, and this average is added to the master well's old setting (the "master setting" of the previous paragraph) to obtain the true master elevation. To find the average elevation change (with respect to the master well 224):

1) Calculate the elevation changes of wells 275-285.

Elevation change = (new elevation setting - old elevation setting), where the old elevation is the last calculated setting found in the most recent computer printout under the heading "NEK ELEVATION".

The above formula expanded is elevation change (with respect to the master well] $=$ [c(cother well reading - master well reading) + master well settingl - other well old settingl. By definition, the master well's elevation change is 0 . A positive change results from a new setting that is higher, which means, as we've seen before, that the well is now lower, or has sunk with respect to the master well. A negative change indicates that the well has risen. Do not calculate an elevation change for a well that has been moved.

2) Compute the average change, disregarding any anomalous values.

3) To obtain the new master elevation, add the average elevaation change to the old setting of the master well. This is 
the value used in calculating the new elevation settings and

elevation changes throughout the ring.

Use the liquid level calibration computer program to calculate the new well settings and the elevation changes. The new setting $=$ [(other well reading - master well reading $]+$ master elevation (found above)]. The elevation change, as before, is inew setting - old calculated setting (see the last computer printout)). A positive change indicates that the well has sunk relative to the average elevation of the wells in region 9. As noted before, an elevation change can not be calculated for wells that have been moved, so in those cases, when computing the elevation changes, input $0.00 \mathrm{~mm}$. as the old setting, which will result in an easily identifiable bogus number. Graph the changes in elevation. check that the charges are of reasonable magnitude and consistent with the past behavior of the $r$ ing in the various regions. A large abrupt change in either direction is likely to be the result of a calibration error (such as air in the water line) or a repositioning of the well since the last calibration (in which case the elevation change can not be calculated). Recheck the calibration of the anomalous well if no error is found in the data reduction.

If the entire PEP system is to be resurveyed, all of the well micrometers are reset to the new values determined above. Write the new settings in the back of the liquid level log book. Cross out the cld numbers.

b) New settings for partial recalibration:

Since it may be neither practical nor desirable to realign all of the elements in the ring during a shutdown, the only wells that should be reset are in those sectors that require resurveying, and the new settings are not necessarily those calculated above. It may be that the function of the machine dictates that only the interaction regions be resurveyed, along with a few sectors in the arcs that have experienced iarge amounts of settling. The "kinks" in the elevation of the elements in these regions are smoothed by adjusting the stands so that the elevation differences between the newly aligned magnets and those that weren't resurveyed are minimized. To calculate the new settings for such a procedure, refer to the graph of the elevation changes constructed above. Oraw a line from one end of the kinked region to the other, connecting the elevation change points of the wells in the areas not to be realigned. New well settings will be interpolated using this line. Notice that the line may be a large fraction of a millimeter above or belaw the horizontal reference axis (which represents the ideal elevation settings), and, in addition, the new line may not be horizontal. The interpolated elevation line merely smooths out the elevation differences in certain areas, without regarding any particular value as absolute.

The amount that a well has settled is found by drawing a 
vertical line from the point representing the elevation change of the well to the interpolated line constructed above, measuring the length of the line in millimeters (on the scale of the graphl, and adding this value to the old well setting if the well has sunk below the interpolated line, or subtracting this value from the old setting if the wall has risen above the line. In other words, the new setting = old setting + amount the well has sunk belcis the interpolated line. For instance, if well 238, whose old setting is $8.95 \mathrm{~mm}$., has risen $0.42 \mathrm{~mm}$. above an interpolated line that includes sectors $233-240$, then the new setting is $8.95-0.42=8.53 \mathrm{~mm}$.

The well settings are unchanged in the cther areas of the ring, including those in which only a few elements are to be resurveyed. Write the changed settings in the back of the lag book.

4) Change the micrometer settings:

a) Set the micrometer of each well to the desired value.

b) Lock the micrometer spindle lock and recheck the setting.

c) Place a Bymo label with the calibration number on well.

5) Shut down the system:

a) close the well values.

b) Make sure that all quick disconnects are attached,

c) Recover the wells.

d) Disconnect the drum at 12B if this hasn't already been done. Drain it and place it in the proton alcove with the three other drums.

\section{Optical Tooling and Equipment}

A. Optical instruments:

1) Precision optical level: The $K$ and $E$ Tilting Level establishes a plane level to 1 second of arc to which elevation measurements are taken. Displacements to thousandths of an inch can be determined at distances up to 100 feet from the instrument, but rarely do shots exceed $35-40$ feet.

2) Jig transit: $A K$ and $E$ Jig Transit establishes a vertical plane along a line between two monuments to which offset measurements are taken. The transit's resolving power is 4 seconds of arc.

3) Optical plummet: The Kern Precision Plummets are used to vertically center laser targets over $r$ ing monuments when laser surveying. The plummet consists of a rotating nadir telescope on which is mounted a 1-second co.ncidence bubble level. Three screks control the level of the plummet. During surveying, a small misadjustment of the bubble level vials is tolerable, but a discrepancy of more than 3 menisci-widths should be corrected in the following manner: 
a) Complete procedure 15] steps 1-4d in the section on laser surveying techniques. The bubble level is centered in one orientation but is 2-3 menisci (or more) out of coinsidence when rotated 180 degrees to its present position (the plummet thus is not yet level).

b) Tighten the rotational locking scres.

c) With the adjusting pins in the plummet carrying casa, slightly loosen the adjusting nuts on one side of the vial.

d) Adjust both nuts until the error is halved. The nuts should be tight when this step is completed.

e) Center the tubble by adjusting the leveling screws with with which the plummet telescope is aligned.

f) Loosen the rotational locking nut and rotate the plummet 180 degrees.

g) Repeat steps b-f until the error is reduced to less than onehalf meniscus.

8. Optical tooling scales:

Optical tooling scales are used when surveying elements in KIT and slT, and wigglers, low field bend magnets, and rf cavities in the ring. The 10", 20", 30", 40", and $60^{n}$ scales consist of standard Brunson Whiteface scales fitted to specially made extenders and tooling ball adapters. For the proper offset and elevation values, add to the transit reading 1" when using the $10^{\mathrm{m}}, 20^{\mathrm{m}}$, and $40^{\prime \prime}$ scales, $10^{\mathrm{n}}$ with the $30^{\prime \prime}$ scale, and $21^{\prime \prime}$ when using the 60" scale.

The 115" scale consists of an engraved $60^{\text {"H }}$ arrett steel scale screwed on to a 55" extender rod and tooling bal, adapter. The fiducial offsets of NIT and SIT magnets Q20, B1D, Q21, and BHI are read from this scale. Add $5^{n}$ to the transit reading to obtain the correct offset measurement.

\section{Optical tooling spheres:}

The 3.5 inch diameter hardened steel optical tooling sphere is set in an adapter mounted on the monument pin. A target mounted in a centered hoie in the sphere provides a reference point for offset measurements when surveying optically or with the laser. The target is mounted so that the patterned face is in the medial plane of the sphere. Thus, the position of the center of the pattern is independent of the sphere's orientation. To recenter the optical target in the sphere:

1) With a spanner wrench, remove the two threaded rings, the collet, and target.

2) Clean and reinstall the collet.

3) Screw in the rear ring until it is finger tight. 
4) Plsce the sphere upside down on the spesial target-centering inisure.

5) Insart the target face cioun into the sphere. The target should rest on top of the fixture.

6) Tighten the rear ring agsinst the collet.

7) Remove the sphere from the fixture and tighten the rear ring as nuch as possible.

8) Reinstall the sront ring (which is not functional).

v. Laser Equipment

A Hamar Hodel 711 laser provides a reference bean (equivalent to an optical line of sight) for elevation and offset measurements in the ring. The laser equipment includes a laser unit, an optical translater which attaches in frant of the laser aperture, photoelectric laser targets, and associated electronics.

A. Laser unit:

The laser unit, which measures about $8 \mathrm{in.} \mathrm{wide} \mathrm{by} 12 \mathrm{in.}$ long by 9 in. high, contains a laser, power supply, expanding and sweep optics, two coincidence spirit levels, and the necessary mechanical adjustments.

The laser housing consists of a base with switchable permanent magnet mounts, a irame wlich can be tilted with respect to the base by coarse and fine adjustment screws, and a horizontally-sweeping turret through which the beam exits, which is turned by hand for coarse adjustments or by coarse and fine azimuth scress for finer adjustments.

The laser output pouer is less than one milliwatt. The logm horizontally exits the laser tube, is reflected 180 dagreez by a dovetailec prism, after which it passes through a series of optical expanding elements, and then a mirror reflects it vertically up into the turret. Two socket-head screws accessed through holes in the side of the laser housing adjust the orientation of the mirror to provide a beam perfectly colinear with the turret's rotationa! axis. The vertical beam either may exit through an aperture on top of the turret, an internal photocell target may be rotated into its path to proyide calibration readings, or an internal pentaprism may be introduced to reflect the beam horizontally through the turret's front aperture. The diameter of the exit beam is approximately one centimeter.

The tuo coincidence spirit levels are used to level the laser to fairly close tolerances, but because the leyel vials may not be exactly parallel to the plane of the turret axis, final laser laveling is accomplished during the buckin procedure. To adjust the the vials with reasonable accuracy, follow the steps below (refer to the procedure for offset buck in in the section on laser surveying for details): 
1) Set the laser on its stand and mount the optical translater on the laser.

2) Calibrate the laser and roughly level it using the bubble leveis.

3) Place an optical tooling sphere target on a stand near the laser. Adjust the height of the target to closely center the beam in the target.

4) Place a second stand and optical target 20 meters from the near target.

5) With an optical level, adjust the far target to the same elevation as the near target ( \pm .003 in.).

6) Replace both optical targets with Jaser targets and readouts.

7) Center the beam on the far target by tilting the laser frame or by rotating the turret.

8) Center the beam on the near target by translation using the slide or the optical translater.

9) Complete the buckin by repeating steps 7 and 8 untif there is no misalignment error. The laser turret is now level in the direction of the beam line (within the accuracy to which the targets were optically set).

10) Center the longitudinal (beam direction) bubble by loosening and retightening the eppropriate adjusting nuts. The laser bubble is now level to within the forementioned accuracy. The following steps will improve the accuracy by adjusting the far target's elevation in accordance with the increasingly accurate laser bubble.

11) Reverse the laser on the stand.

12) Level the laser using the coincidence levels.

13) Horizontally buck in the laser, starting with the far targets.

14) Vertically center the laser on the near target with the optical translater. The bubbles (especially the longitudinal bubble) should still be centered. If not, recenter them and repeat the buckin.

15) If the far target registers less an $\pm 0.05 \mathrm{~mm}$. ( $\pm .002 \mathrm{in}$,) on the vertical scale of the readout, the target elevation and bubble adjustment are good. Otheruise, do the following:

a) Vertically adjust the far target stand to reduce the misalignment by half.

b) Tilt the laser housing to vertically center the beam.

c) Recenter the longitudinal bubble using its adjustment nuts.

d) Repeat steps $11-15$ as necessary.

16) Calibrate the second coincidence spirit level as above, The laser stand must be turned 90 degrees.

17) The bubbles may go out of adjustment after they are calibrated, but it is sufficient if they will help center the beam to within $\pm t \mathrm{~mm}$. on the far target. 
B. Optical translater:

The optical bean translater consists of a parallel ground circular plate of glass mounted in a frame and gymbals which can rotate on the two axes parpendicular to the bea:n. The two air-glass surfaces refract the beam equally and in opposite directions so that the bean is displacad witrout leing changed in angle. The maximum possibie bean translation in either direction is rather small (less than $2 \mathrm{~mm}$.), so that during buckin, the inajor portion of the bean translation is done by adjusting the side and the stand's fine elevation sorew.

\section{c. Laser target:}

A Hamar 2-axis quadrant photoceli target is mounted in 3 housing machined to precisely fit in a 3.5 in. diameter optical tooling sphere, SAM, ARM, and the liquid level rods. The target cell face is $1.000^{\prime \prime}$ from the rear edge of the sphere so that it is in the sphere's center plane, as wauld be an optical target. Periodically, the centering of the Hamar target cell should be checked and sojusted if necessary (also refer to LEL Engineering Note M5581):

1) Sat the laser and optical plummet on the laser stand.

2) Set the sphere and target on the plumet and connect the readout. The iarget should be correctly oriented "up".

3) Roughly center the beam in the target.

4) Precisely center the laser beam in the target:

a) Bring both scales of the readout to $0.00 \mathrm{~mm}$. using the optical translater.

b) Rotate the target 180 degrees.

c) Using the translater, halye the readings on both scales.

d) Rotate the target 180 degrees. The errors should be the same (the signs are reversed). If nct, halve the reading differences and repeat steps $b-d$.

e) Check the readout values at 90 and 270 degrees. The horizontal and rertical scale values will be interchanged. The laser beam is now exactly centered in the target.

f) If the readout numbers (centering errors) are greater than $\pm 0.02 \mathrm{~min}$. , adjust the targat position as follows:

1) Remove the target from the sphare.

2) Remove four socket-head cap screws and the end cover from the target mount. Note the relative position of the end cover to the target mount - they must be reassembled in the same way. 
3) Inside of the end cover are four machine screws which secure the target photocell. Loosen the serens just enough to permit the repositioning of the photecell.

4) Rerrove the four outer set screws from the target barrel.

5) Keeping in mind the direction of the centering errors found above, adjust the four inner set screus to recenter the targat. Each set screw has a 32 threadsrinch iead, and yill move the target cell 0.031 in. rrevolution.

6) Reassemble the target.

7) Recheck the centering of the target as above.

8) The calibration of the target is ccmpleted when the centering errors are less than $\pm 0.02 \mathrm{~mm}$.

\section{Automatic Readout Instruments}

A. Small Automat o Micrometer (SAM) and liquid level rods (fig. 16):

The Small Automatic Microneter (SAM) provides elevation measurements in the PEP ring. A laser is bucked in to the elevation of tho liquid level rods resting on wells on either end of the sector. SAM is set on a ring magnet fixture ficucial ball and its target is raised or lowered to center on the beam. The length to which SAM has been extended is automatically input into the computer by pressing a button.

1) Small Automatic Micrometer:

A Mitutoyo $50 \mathrm{~mm}$. micrometer and a suiveling 1 ser target holder are mounted on the body of SAM. The tip of the micrometer is embedded in an assembly which receives the ring magnet tooling ball. As the micrometer drum is turned, SAM is raised or lowered with respect to the fiducial ball. At the same time, an electronic signal is sent by the micrometer to a Mitutoyo readout on the cart which records the change in SAM's length from a precalibrated value. SAM is made plumb by means of a bubble level, and then SAM's target is vertically centered on the laser beam by nulling the vertical scale on a Hamar readout which receives signals from the photocell in the target. The laser turret is rotated to center the beam horizontally in the target. When the target readout shous $0.00 \mathrm{~mm}$. on both scales, and the bubble leval is centered. SAM is correctiy oriented to measure the vertical ofiset, or elevation. from the fiducial ball and the laser beam. SAM's length, as displayed on the Mitutoyo readout, is input into the computer by pressing a button on SAM.

During the elevation measurement, SAM is held plumb by a flexible indicator holder. One end of the holder is attached to a ring magnet or a steel tripod plate by means of a suitchable permanent magnet, and the other end is screwed to a shaft on a vertically-sliding steady-rest on SAM. This arrangement allows SAM to move vertically without changing its plumb orientation. 
The calibration number far SAM should be checked periodically. To do this, open SAM to its calibration length (see the section on elevation measurements for detailsl, and with optical toaling, measure the distance betwsen the centers of the target holder and the tooling ball. This is the new caliuration number, and it should correspond to the number on SAM's engraved plate.

Two liquid level rods provide an elevation reference for the buck in of the laser. On the lower end of the rod, a press-fitied carbide button rests on a liquid level well micrometer tooling ball. On the upper end of the rod is a laser target holder. The rod is made plunb when the bubble level is centered by adjusting the rod's flexible holder. SAM's target is rotated to point at the laser beain by revolving the entire rod in the swiveling sieady-rest to which the flexible holder is attached. The target holder should not move relative to the rod; if it does, the mounting screw must be tightened. The length of the liquid level rod, from the center of the tooling ball to the center of the target, is a nominal $58.820 \pm .002$ in. Periodically, this dimension should be benchchecked with optical tooling.

B. Autumatic Readout Micrometer (ARM) and standard gage (Fig. 17):

The Automatic Readout Micrometer (ARM) measures the horizontal offset between a $r$ ing magnet fiducial ball and a reference laser beam that is centered over two survey monuments. Aiter ARM has been extended to measure this distance, its length is automatically input into the computer by pressing a button.

1)

\section{Operation:}

ARM is first set to a pre-calibrated length on the standard gage on the cart (see the section on laser surveying techniques for the calibration procedure). Then, ARM's tooling ball socket is fitted over a magnet fixture fiducial ball and $A R M$ is rested on a leveling stand. Turning the coarse or fine thumb wheel extends a telescoping tube into the aisie until the target intersects the laser beam. As the tube extends, it draws an internal steel tape over a rotary gage block-optical encoder assembly which senos electronic signals to the KIII readout on the cart corresponding to the changes in the length of ARM. Using the laser target raadout scales as a guide, ARM is correctly positioned and the target is centered on the beam. The button on ARM is pushed, inputting the number on the KIII readout (ARM's length) into the computer. Components :

The major components of ARM are a tooling ball socket, an encoder tape unit, a gear box, and a telescoping arm to which is attached a laser target.

The hardened stainless steel tooling ball socket accepts a $1 / 2$ in. diameter tooling ball. There are two versions of the socket, 
one of which has an internal teflon o-ring which helps to prevent the socket from accidentaly slipping off the fiducial ball.

because some force is required to slip the o-ring over the tooling ball. it is easy to jar ARl enougn to cause it to lase calibration. Therefore, the second type of tooling ball socket, without an oring, is most often used.

The encoder tape unit houses the Aerosmith KIIl measuring

system, a momentary push button switch, and a 10 pin connecticn for a cabie leading ts the electronics on the cart. As the telescoping tube is extended, it pulls a 100 in. long stainless steel tape from a storage drum over an Invar rotary gase block, which drives the shaft of an optical encader thraugh a series of anti-backlash gears. The encoder sends an electronic signal to the cart. A nscater sfring assembly supplies constant tension to the tapa through the storage drum.

The gear box contains two thumb wheeis, two sets of gears, a slif clutch, a planetary reducer, and an output shaft. The gears and the planetary reducer produce a reduction ratio of 23:1 from the fine sheel to the coarse wheel. The slip clutch, between the two thumb wheels, is adjusted so that the fine wheel drives the coarse wheel, but will slip when the coarse wheel is turned. The gear box turns a long smooth output shaft which drives a threadless nut in the telescoping arm assembly.

The telesroping arm assembly cansists of a stationary outer tube, a telescoping inner tube, a threadless nut, a 3 pin connector for the laser target cable, and a laser target holder. The threadless nut is a spring-ioaded split nousing on which roller bearings are mounted at an angle. The housing fits around the gear box output shaft, and is mounted inside the hard anodized aluminum inner tube. This tube rides along Rulon bearings inside of a stationary outer tube, and is prevented from rotating inside of the outer tube by an internal key. The threadless nut, since its housing is prevented from turning, will move zlong the rotating gear box output shaft, moving the inner tube with it. Also, the threadless nut is designed to slip along the shaft if a pre-set load init is exceeded. This feature makes it possible to rapidly change the length of ARM by pushing on the tube, without having to turn the thumb wheels.

On the end of the telescoping arm is the target holder and a removable laser target. The target is radially aligned by means of spring-loaded ball plungers in the holder and detents in the target.

3) Maintenance:

ARM is normaliy reliable in operation, ard the internal components need i ittle special attention. The laser target, of course, must be centered as described previousiy. The cable betieen ARM and the "blue box" on the cart may occaisionally malfunction, requiring replacement. other maintenance and repair procedures are described in LBL Engineering Note M5581. 
4) ARM standard gage:

The ARil standard gage is used to adjust ARM to a precalibrated length just before offset measurements are taken. ARM's fiducial ball socket fits over a tooling ball on one end of the gage and ARM is extended until an adapter ring in ARM's target holder fits over a second tooling ball on the other end of the gage. The KIII readout is then set to the premeasured distance between the two tooling balls.

The gage consists of two $1 / 2$ in, diameter tooling balls mounted on end plates which are rigidly held together by two thermally stable Invar rods. One end plate is attached to an aluminum base and the other is free to move as the base expands and contracts due to temperature changes. The distance between the centers of the tooiing balls is the calioration number of the gage, and it should be periodically checked (to $\pm .01 \mathrm{~mm}$. ) in the lab using optical tooling.

C. Automatic Readout Tape Unit (ARTU) and extension tapes (Fig. 18):

1) Dperation:

The Autamatic Readout Tape Unit (ARTU) measures lengths (slant distances) up to $25 \mathrm{ft}$. Its range can be extended by using a 25 $\mathrm{ft.}$. $50 \mathrm{ft}$. , or $75 \mathrm{ft}$. Invar extension tape. ARTU contains an Ideai-Aerosmith KIII Linear measurement system, which works as follaws: a stainless steel tape, when pulled from the ARTU body, travels over a rotary gage block, which, by means of an encoder, sends an electranic signal to a readout on the cart. The readout displays the length of the extended tape in millimeters or inches. The reierence end points of the slant distance measurement are $1 / 2$ in. diameter tooling balls mounted on magret $f$ ixtures, or, as in NIT, SIT, and the RF cavity regions, mounted directly on the element. The ARTU body has a socket that accepts one of the fiducial balls and the female tape end accepts either the other fiducial ball or the male end of an extension tape. After ARTU has been extended between the fiducial balls and oriented properly, a button on ARTU is pressed which inputs the number on the KIII readout into the computer. A negator spring assembly supplies severai pounds of constant tension to the tape through the tape storage drum. The tension serves both to enable consistent siant distance measurements by preventing undue tape sag and to retract the tape after the reading has been taken. To prevent damage to the ARTU components and to improva the accuracy of the readings, the rate of the tape's extension and retraction is moderated by an adjustable rotary dashpot. 
ARTU calibration:

ARTU's caliuration number is tlae distance between the centars of its two tooling ball sockets when the tape is fully retracted. This number is preset on the readout before the tape is extended, and upan retraction of the tafe, the readout should cisplay a number clase to it (the difference between the two numbers is a measure of the inaccuracy of the reading caused by slippage of the tape over the gage block; for an acceptable reading, the error should be less than. $50 \mathrm{~mm}$.). The calibration number for each ARTU is different, and after many hundreds of measurements, it may change sightly due to wear of the gage black. Dccaisionaliy. RRTU shculd be recalibrated on the SLAC Alignment $100 \mathrm{ft}$. tape bench below the linac at sector 10. The calibration number is found by extending the ARTU tape to a measured length, presetting the readout to thai disiance, and retracting the tape. The number on the readout is the ARTU calibration number. ARTL has previously been cilibrated thice: on August 21, 1978 (see Survey 0ata Log Book I, page 10) and on Dotober 29, 1980 (see Survey Data Log Book $x$, page 64). As the calibration proceeds as described below, record the results in the survey Data Log Book.

a) Six tooling ball holes have been drilled in tive $00 \mathrm{ft}$.

tape bench. The distances from five of the holes to the $0 \mathrm{ft}$. hole were measured August 16, 1978, and are as follows:

$35.997 \mathrm{in.}$ (about $3 \mathrm{ft}$.)

240.003 in. ( " $20 \mathrm{ft}$.

360.003 in. ( $n 30 \mathrm{ft.})$

660.000 in. (" $55 \mathrm{ft.}$ )

960.001 in. (" $80 \mathrm{ft}$.)

ARTU will be extended between the tooling ball at $B$ it. and ore at one of the above distances.

b) Place a 1 in. long tooling ball at $0 \mathrm{ft}$. and one at $3 \mathrm{ft}$.

c) connect ARTU to the readout and prepare to take readings. in the readout, dial in the calibrated disterce of the $3 \mathrm{ft}$. hole: 35.997 in, (the readout should be on the English units scale).

d) Place ARTU on the tooling ball at $0 \mathrm{ft}$.

e) Extend the tape to the $3 \mathrm{ft}$. tooling bull. Make sure that the readout numbers increase as the tape is extended sif not, reverse the direction switch on the readout).

f) Find the smallest readout number by arcing ARTU.

g) Push the readout's preset button. The display should read 35.997.

h) slowly retract the tape. The final readout value should be approximately 4.530 in. Record the number.

i) Repeat steps $e^{-h}$ four more times. The rumbers should be be within 0.005 in. of the average value. If not, check the setup for errors and take additional readings.

j) Average the five numbers.

k) Repeat the steps above with a tooling ball at $20 \mathrm{ft}$, and with the readout preset to $240.003 \mathrm{in}$. The larger distance is a 
check for scaling error of the gage block. If the gage block is very Horn. it will no longer be accurate over all distances. This would be reflected by different values for the calibration number when the tape is extended to varying lengths. The original ARTU calibration detected a scaling error in each instrument, but subsequent use of the ARTU has worn the gage blocks sa that the scaling error has been nearly eliminated.

1) Average the two mean values abtained above. This is the ARTU calibration number (in inches). Write the number (in millimeters) and the date on the ARTU identification plate.

The calibration numbers of the $25 \mathrm{ft} ., 50 \mathrm{ft}$., and $75 \mathrm{ft}$. Invar extension tapes represent the length between the centers of the male tape end tooling ball and the female tape end socket. This distance may change over time due to the tape stretching or being bent or kinked during use. The length is found by attaching the tape to an ARTU that has been recentiy calibrated, presetting the KIII readout to the ARTU calibration number, extending the female tape end to the nearest tooing ball on the $100 \mathrm{ft}$. tape bench, and subtracting the readout number from the calibrated tooling ball distance. Record the calibration procedure $c: J$ results in the survey Data $\log$ Book.

a) Set up ARTU and the KIII readout. Dial in ARTU's calibration number in inches on the readout. which is set on the English units scale.

b) Unrall the $25 \mathrm{ft}$. extension tape and attach the female tape end to a tooling ball in the $30 \mathrm{ft}$. hole.

c) Extind ARTU's tape end and attach it to the extension tape. straighten out the tape as much as possible, but do not add any extra tension to it as the calibration proceeds.

d) Arc ARTU to find the smallest readost number (it will be about $60.125 \mathrm{in.}$. . Record the number and slowly retract the tape. Make sure ARTU recalibrates to within \pm .005 in.

e) Push the readout's reset button and repeat the steps above four more times.

f) Average the five readings and check for consistency ( \pm .005 in.).

g) Subtract the average value from the $30 \mathrm{ft}$. hole's distance $(360.003$ in.) to get the tape's calibration number in inches.

h) Update progrem MEASURE, averlay 1, step 3270 with the new $25 \mathrm{ft}$. extension tape calibration number in millimeters. Also write the number and date on the tape reel.

i) Repeat the calibration procedure with the $50 \mathrm{ft}$. and $75 \mathrm{ft}$. extension tapes, using the appropriate tooling ball holes and distance measurements (see the ARTU calibration procedure for these values). Update progran MEASURE, Overlay 1 , steps 3290 and 3310 with the new $50 \mathrm{ft}$. and $75 \mathrm{ft}$. tape calibration numbers, respectively.

4) ARTU cleaning (see drawing AD-201-132-D1-RO-E for details): Periodically ARTU should be cleaned, especially when the tape 
slips over the rubber wheels upon retraction. This occurs when dirt from the tape transfers to the rubber, building up a slick surface on the wheel. The path of the tape as it enters the ART'J body is as follows: tape cleaner body (layers of neoprene and felt), No. 3 steel wheel, No. 2 rubber wheel, No. 1 rubber dashpot wheel, rotary gage blook, and the tape storage drum.

a) clean the steel tape by extending and retracting it through an alcohol-soaked rag.

b) REmove the steel and aluminum side covers from ARTU.

c) slightly extend the tape and insert a small allen wrench or sirilar object through one of the holes in the tape storage urum into a small hole in the mounting plate. Allow the tape to retract. When the storage drum jams against the allen wrench, the tape will become slack.

d) Prevent the tape from unwinding from the storage drum by stretching a rubber band around the drum.

e) Remo:e the No. 3 whesl cover, the composition thrust washer, a roller-bearing wheel, and another washer.

f) Remove the No, 2 wheel cover, the nylon thrust washer, a rubber wheel, and another washer.

g) Remove the dashpot and a rubber o-ring. Do not remove the rubber wheel from the dashpot.

h) clean the rubber and steel wheels, the washers, the rotary gage block, and the interior of ARTU with alcohol.

i) Lightly grease the roller bearings with Lubriplate.

j) Replace the tape cleaner components:

i) Remove the internal circlip with a special tool.

2) Replace the two pieces of neoprene and six pieces of felt. The neoprene half-circles are inserted so that their notched corners are both on one side of the tape cleaner body.

3) Replace the circlip with the open end opposite the notches of the neoprene pieces.

k) Reassemble the ARTU components.

1) Remove the allen wrench and allow the tape to retract.

m) Replace ARTU's side covers.

VII. Magnet Roll Instruments

A. Injection magnet roll fixture:

1) Operation:

The injection roll fixture measures magnet roll normal to the beam $l$ ine in NIT and SIT. It is similar in design to a sine-bar. and consisis of a top plate hinged to a base, and a bubble level and a digital readout micrometer mounted on the top plate. The fixture is placed on the upper surface of a masnet perpendicular to the beam line. By turning the micrometer, the angle of the top plate with respect to the hase is changed and the bubble is centered. The number $N$ (in inches) on the micrometer's digital 
reacout is typed into the computer, which converts the reading into radians $R$ for further use, using the formula $R=(2-K) / 10$.

The roll fixture base is made of teflon coated hard anodized alurincm plate. Three spherical buttons are pressed into the bottom of the base. A hardened tool steel pin acts as a hinge between ane end of the base and the top plate. A Mitutoyo digital readout micrometer is mounted on the other end of the top plate. The center of the micrometer shaft is 10.030 in. =rom the center of the hinge pin, measured along the top plate. The micrometer has a 2 in. rairge and is gradiated in divisions of .001 in. on the reacout and $.0002 \mathrm{in}$. on the vernier soale (which is not used). The micrometer shaft's ball end is free to slide along a plate in the fixture base as the micrometer is turned. A 60 second tubular bubble level is mounted in the center of the top plate. Calibration:

If the roll fixture is placed on a level surface and the bubble level is centered, the micrometer should read 2.000 in. on both the digital readout and the vernier scale. If this is not the case, the fixture should be recalibrated using the following procedure:

a) Place the injection roll fixture on a level surface.

b) Turn the micrometer to center the bubble.

c) Set the digital readout to 0.000 in. by using a screwdriver to press the small black reset button.

d) Reverse the fixture. The bubble should still be centered.

e) Raise the micrometer until the digital readout is at 8.000 in.

f) Push the reset button to set the readout to $0.000 \mathrm{in}$.

g) Lower the micrometer and center the bubble. The readout should be at 2.000 in.

h) Set the micrameter drum's vernier scale to exactly $2.000 \mathrm{in}$. by holding the upper knurled edge of the drum while twisting the drum skirt below (it is a slip fit).

B. Talyvel (Fig, 2)

1) Operation:

The Rank Taylor Hobson Talyvel measures ring magnet roll normal to the beam line. The Talyvel consists of a meter unit and a level unit interconnected by a cable. The Talyvel is calibrated prior to roll measurements (see the section on laser surveving techniques). Then, the level unit is clamped into a ring magnet fixture. The amount of roll is indicated by the meter or by the the graduated leveling knobs in units of inches/inch (which are equivalent to radians for small angles).

2) Components:

a) Level unit: The Talyvel level unit contains in its housing a pendulum - electrical sensing system subassembly. The angular orientation of the subassembly with respect to the housing is 
adjusted by leveling knobs on top of the level unit. The dampes pendulum is suspended by five wires. It is resirained from moving freely if the level unit's sidenays $t i l t$ exceecs one degree. The pendulum's damping permits the meter fointer to come to rest within one secono but also allows raadings on the most sensitive scale in the presence of slight vibration. A transducirg coil on each side of the penduium comprise an industive bridge circuit that senses the attitude of the pendulum and sends an electrical signal to the meter unit. The roli reading depends on two factors: the angle between the pendulun - bricige circuit subassembly and the bousirg, which is given by the leveling knob scales, and the distance between ihe pendulum and the sensing coils of the bridge circuit. which is transformed into angular or gradient units and read off of the meter.

The two micrometer-type leveling knous are scaled with five vertical graduations on the spindle and fifty ioorizcntal graduations encircling the barrel of the knob. Each spindle division r:presents .010 radians of roll. The shird graduation is elongated and represents the center of travel of the knob and arbitrarily is used as a zero reference. Each division on the barrel represents .0002 radians; thus a full rotation of the barrel through fifty graduaticns represents a change of .010 radians, and correspondingiv, a single spindle graduation is exposed or covered up by the barrel. The leveling knobs have three functions: 1) when screwed all the way down, the knobs force the pendulum against a resilient abutment to prevent movement during transport; 2) when unscrewed to the fullest extent, the pendulum is unrestrained and the pendulum - bridge circuit subassembly is made perpendicular to the level unit base, so that the Talyvel acts as an absolute level; and 3 ) when the two knobs are set to intermediate positions, the subassembly is tilted by the difference in the amounts indicated on the scales of the knobs. By using this last mode of operation, rolls can be measured which exceed the range of the meter $( \pm .0025$ radians), up to a maximum of \pm .040 radians (a little over 2 degrees). The level unit normally is operated either with both knobs set to the zaro mark, in which case the reading is displayed on the meter, or, when the Talyvel meter range is exceeded, with one knob set to zero and the ather adjusted to null the meter, in uhich case the reading is taken off of the non-zero knob.

b) Meter unit: The meter unit carries four conirols on the top, three push button switches behind the rear cover, a meter movement, and a battery operated transistorized amplifier. It aiso contains storage space for the level unit and cable.

The balance control screw, underneath a dummy knois, adjusts the electrical balance of both the inductive and resistive elements of the bridge circuit. The zero adjuster knob adjusts the meter zero. The approximate pasition of the knob is marked, 
but its exact position may be slightly to one side of the mark. The range suitch has four settings: 0FF, 8 min., 100 sec,, and 50 sec. Roll readings are taken using the $8 \mathrm{~min}$. range. The meter, when in the 100 sec. range, is about five times as sensitive as in the $8 \mathrm{~min}$. range. This scale is used only during Talyvel calibration. The 50 sec. range, which is ten times as sensitive as the $8 \mathrm{~min}$. range, is not used. The gain control, below a duminy knob, adjusts the meter reading to correspond with the movement of a leveling knob. The meter zero and balance switches behind the rear cover are used in conjunction with the control knobs to check and adjust the Talyvel.. The battery volts switch is pressed to check the battery power. If, when the suitch is pressed, the meter pointer travels only as far as the left margin of the red square on the meter face, the batteries should be replaced. The two Mallory batteries (type SKB-830) provide a nominal 6.7 volts when new, but the Talyvel will operate with the voltage down to 4.5 valis. To remove the batteries, open the back cover of the meter unit, remove the level unit, loosen two screws and remove the battery clamping plate, and detach the snap connectors from the batteries.

The Talyvel level unit is normally mounted on the magnet fixture with its cord towards the aisle. In this position, when the pointer is centered on the meter face, the rall is 0 (the magnet is level). If the pointer is to the right of center, the roll is positive (the magnet is tilted away from the aisle), and if the pointer is to the left of zero, the roll is negative (the magnet is tilted towards the aisle). Measurements in each of the three ueter ranges (8 min., 100 sec., 50 sec.) can be read in angles (minutes or seconds) and in gradients (inches/inch and millimeters/meter). of these nine types of readings, eight are read off of the upper graduated arc on the meter face, with only angular measurements in the $8 \mathrm{~min}$. range being read off of the lower arc. The advantage of having only two arcs is the simplicity of taking readings and converting from seconds of arc to gradients, but the following compromise has been made that slightly reduces the accuracy of the measurement. The applicable theoretical relationship of gradients to angles (to three significant digits) is $.000485 \mathrm{in.} / \mathrm{in} .=100 \mathrm{sec}$. This has been approximated on the meter scale by .0005 in. $/$ in. $=100$ sec. In this way, the seconds scale shares the same graduations with the gradients scales of $i n . / i n$. and $\mathrm{mm}$. AM. This compromise introduces a $3 \%$ error when comparing the gradient to the angular scale. However, since the calibration and use of the Talyvel involves only the gradient scales, this error is not imporiant.

3) Check the absolute roll reading accuracy of Taiyvel:

Talyvel's absolute accuracy is not normally checked during its calibration. The following accuracy check may be done periadically: 
a) Se: the bend magnet fixture calibration knee on a level granite slab.

b) Piace a recently calibrated bend magnet fixture on the knee, with the micrometer set to $00.00 \mathrm{~mm}$.

c) Calibrate Talyvel (see the section on laser surveying techniques).

d) Measure the roll of the fixture - it should be 0 .

e) Remove the level unit and the bend fixture from the knez.

f) change the fixture aicrometer $5 \mathrm{~mm}$. to $95.00 \mathrm{~mm}$. and lock the spindle. Replace the fixture on the knee.

g) Measure the fixture roll (r) using the leveling knobs to null the meter. Either the $8 \mathrm{~min}$. or 100 sec. soale may be used. The distance from the center of the micrometer spindle to the center of the upper tooling ball is $270 \mathrm{~mm}$., and the fixture's displacement from vertical at the nicrometer is $5 \mathrm{~mm}$. Therefore, the correct reading of the non-zero leveling knob can be found by applying the formula $\sin (r)=r=5 / 270=0.0185$ racians. 
REFERENCES

Bend Magnet Fixture Calibration: PEP Orawing No. QT-201-130-24-RO-E.

Monument fssembly: PEP Orawing NO, AD-201-123-00-RO-E.

Liquid Level Well Assembly: PEP Orawing No. AD-201-125-00-R 1-D and $A D-201-125-20-R T-E$.

Liquid Level Hell Installation: PEP Orawing No. AO-201-125-32-RO-E.

ARM and Laser Target Maintenance: LBL Engineering Note M5581.

Instruction Manuals: Talyvel Level

Hamar Laser

General Infarmation:

"The PEP Laser Surveying System," T. Lauritzen and R. C. Sah, IEEE Iransactions on Nuclear Sciance, Vol. NS-26, No. 3, June 1979.

"The Recent High Precision Surveys of PEP," R. C. Sah, LBL Publication L 8 L 12006 , December 1980.

"The PEP Liquid Level System," T. Lauritzen and R. C. Sah, LBL Publication LBL 11747, March 1981. 


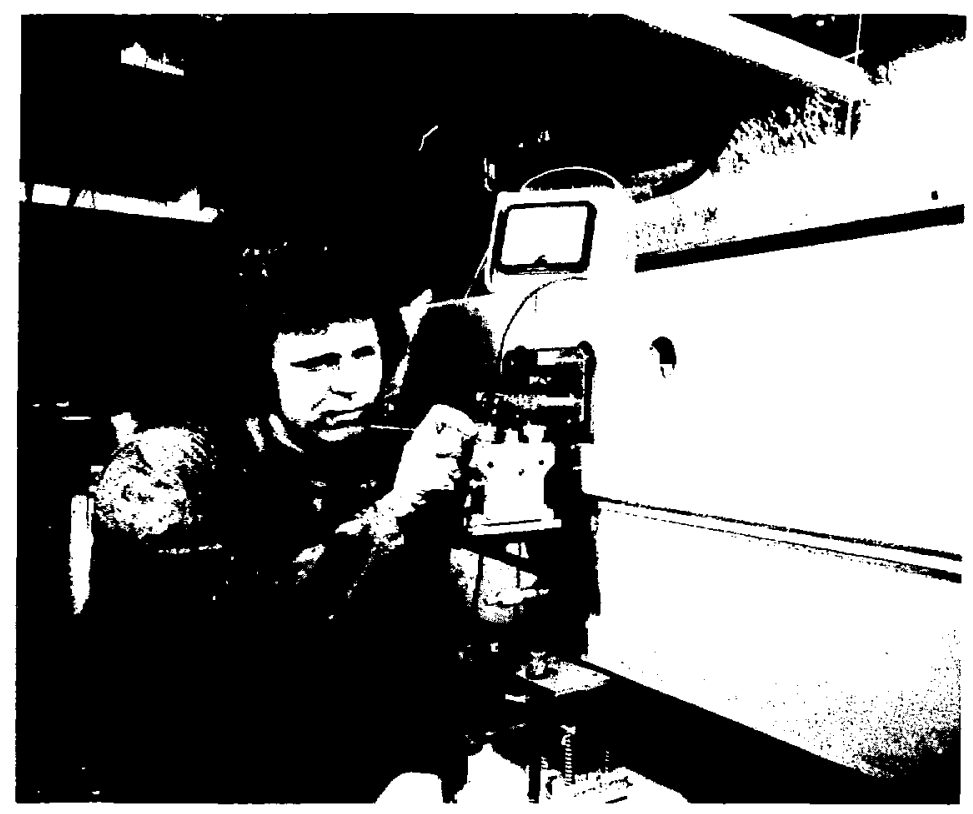

Fig. 1. Measuring bend magnet roll: Talyvel mounted on bend magnet fixture. 


$$
\text { 畐 }
$$




$$
\text { 自 }
$$


$-67-$

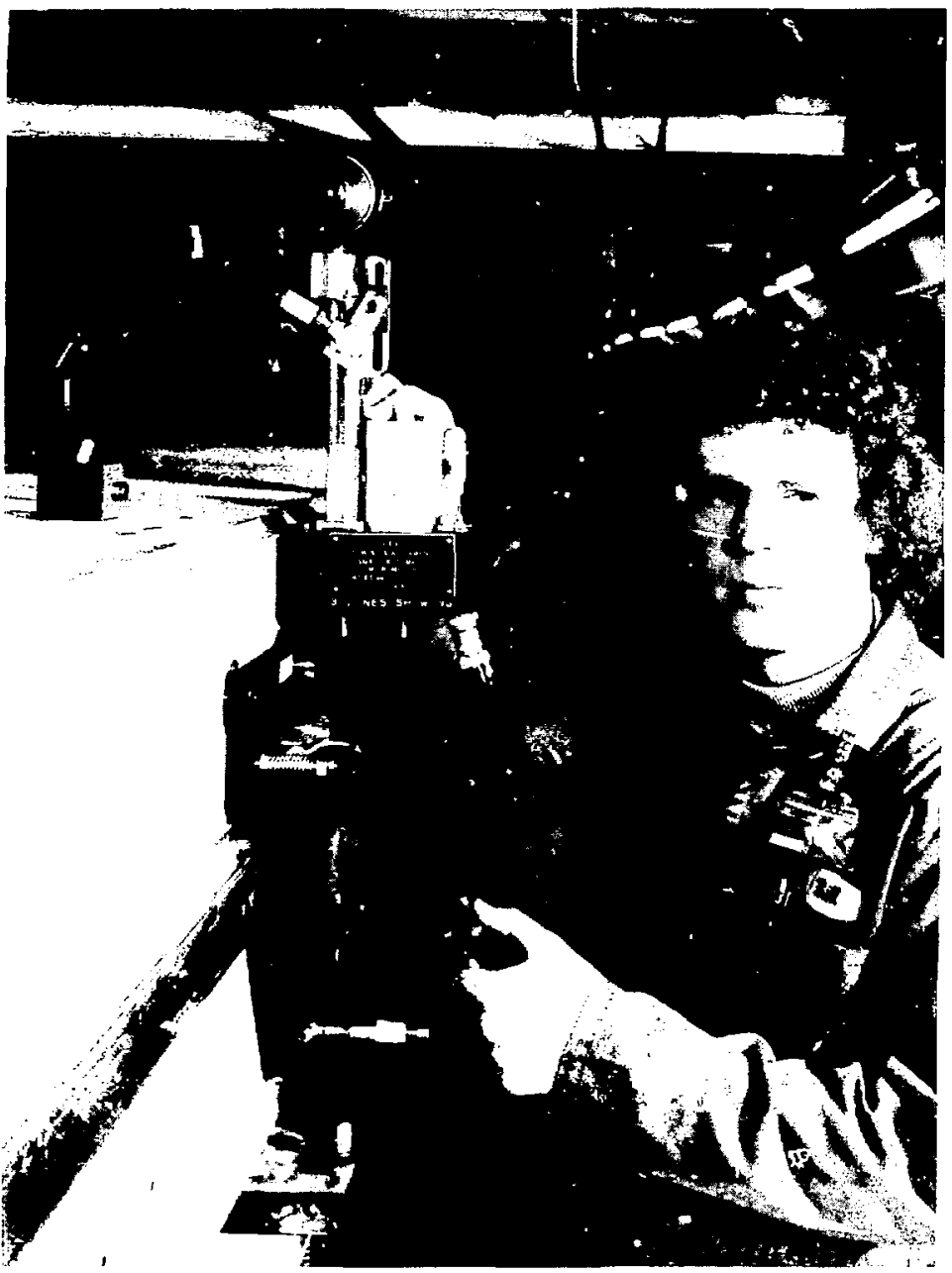

Fig. 4. Measuring bend magnet elevation: Small Automatic Micrometer (SAM) an bend magnet fixture. 


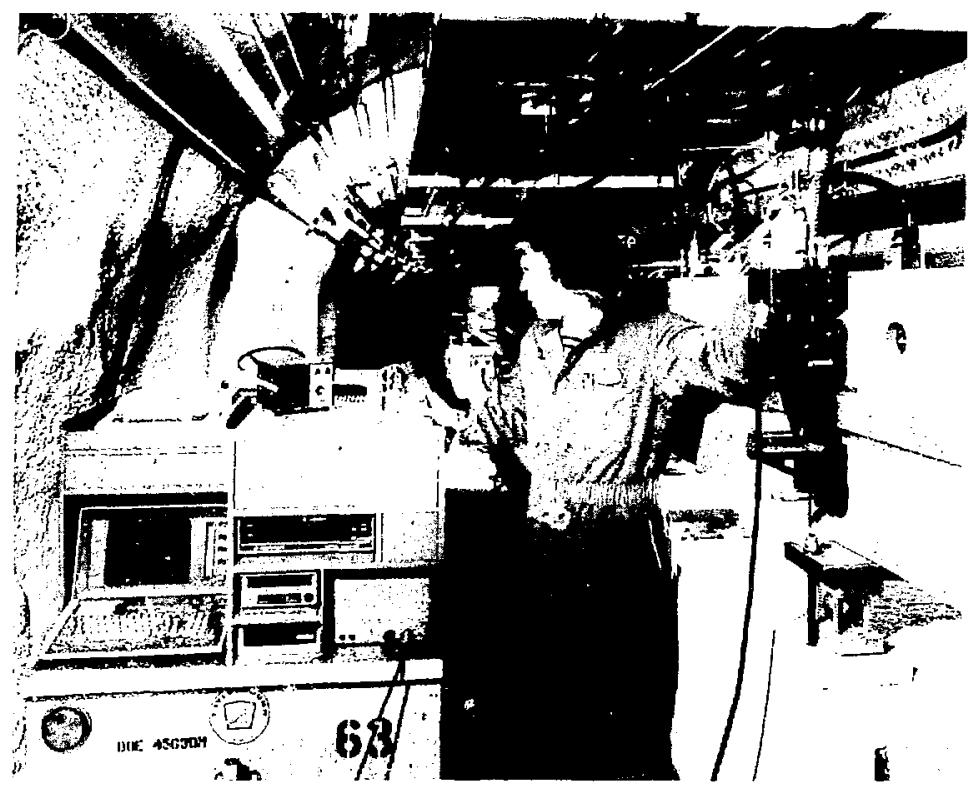

Fig. 5. Measuring bend magnet elevation: SAM, readouts, and computer. 


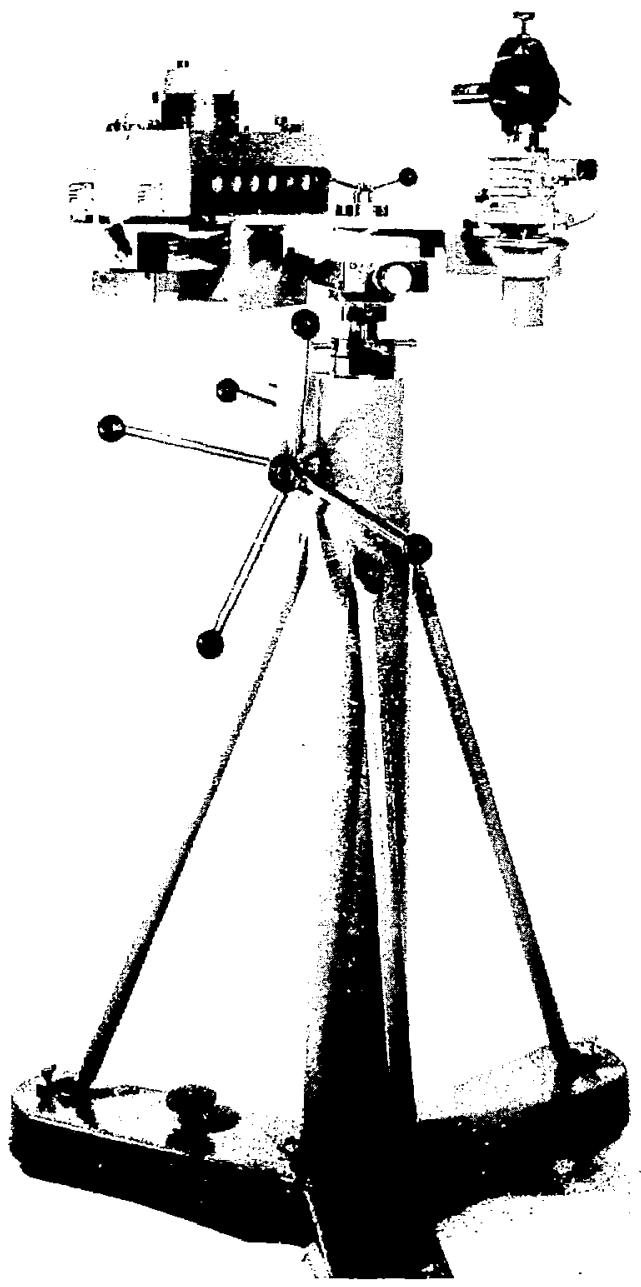

Fig. 6. Laser stand prepared for offset measurement buckin: laser, optical plummet, laser target. 


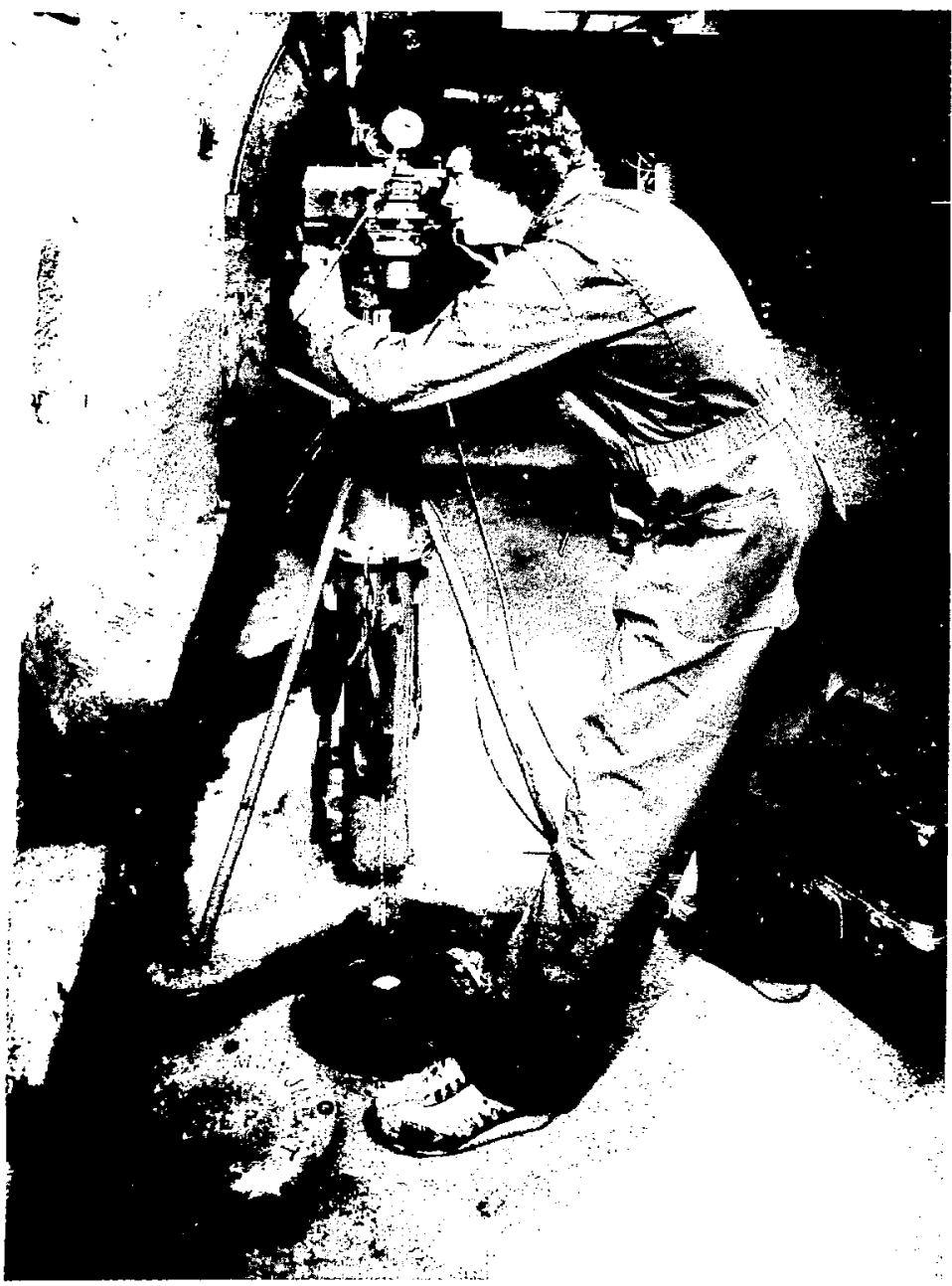

fig. 7. Leveling and centering optical plummet over monument target. 


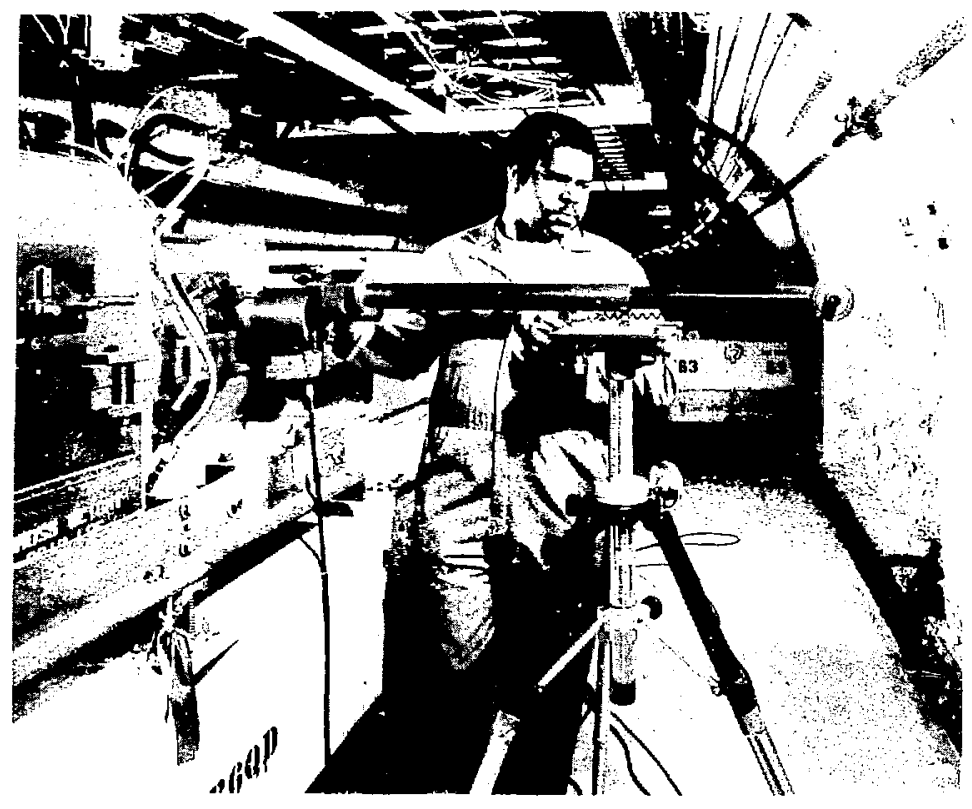

Fig. 8. Measuring sextupole offset: Automatic Readout Micrometer (ARM) resting on sextupole fixture and tripod. 


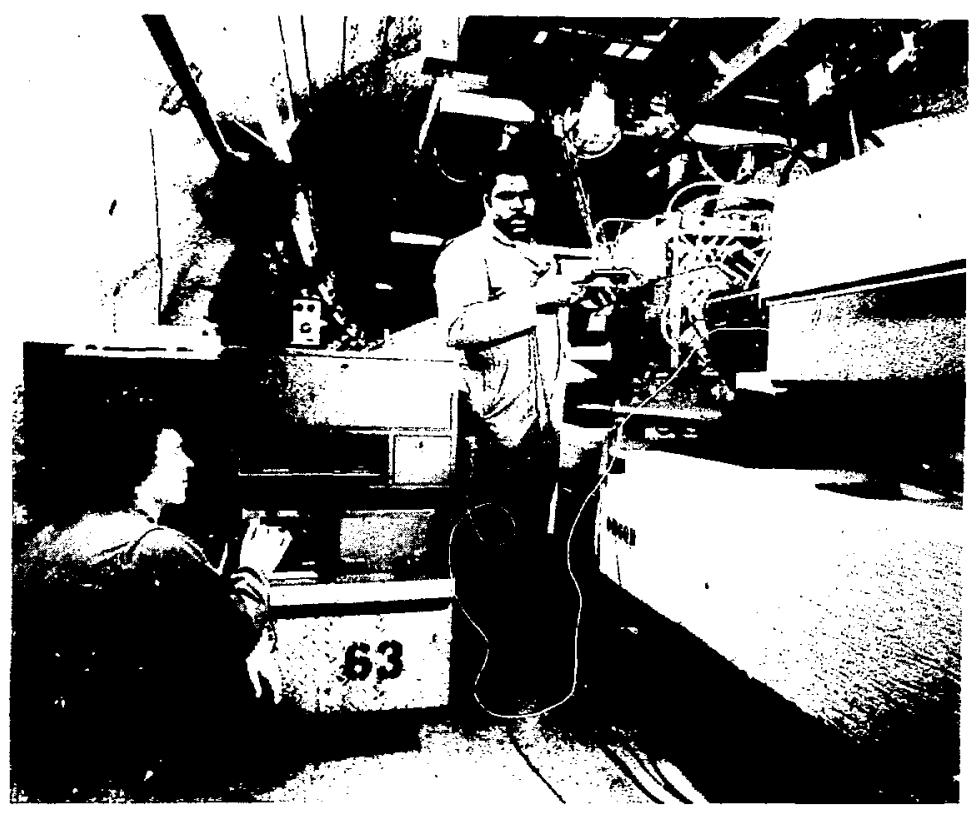

Fig. 9. Measuring slant distance between quadrupale and sextupole: Automatic Readout Tape Unit (ARTU) mounted on quadrupole and sextupole fixtures. 


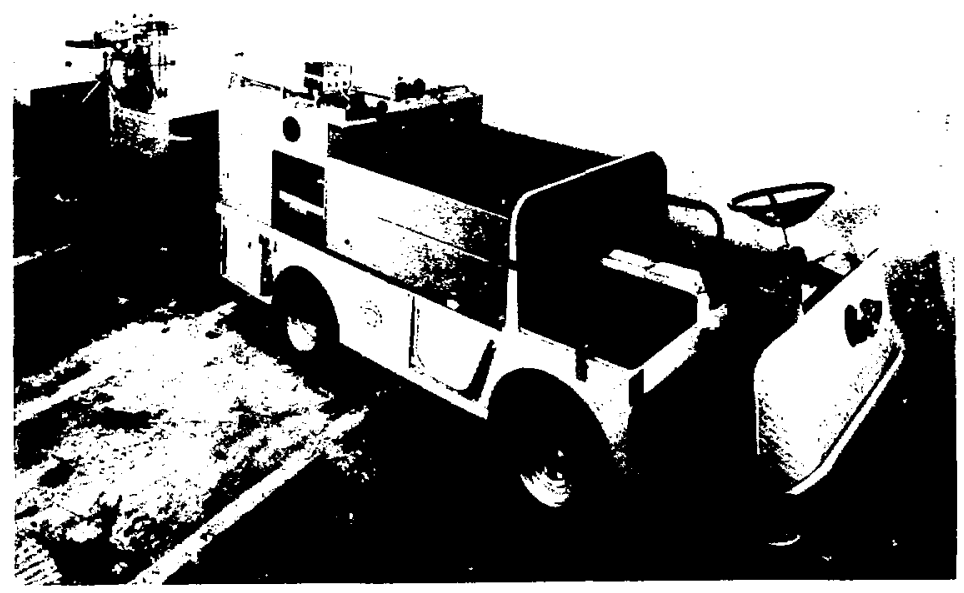

Fig. 10. Eloctric cart, trailer, laser stands. 


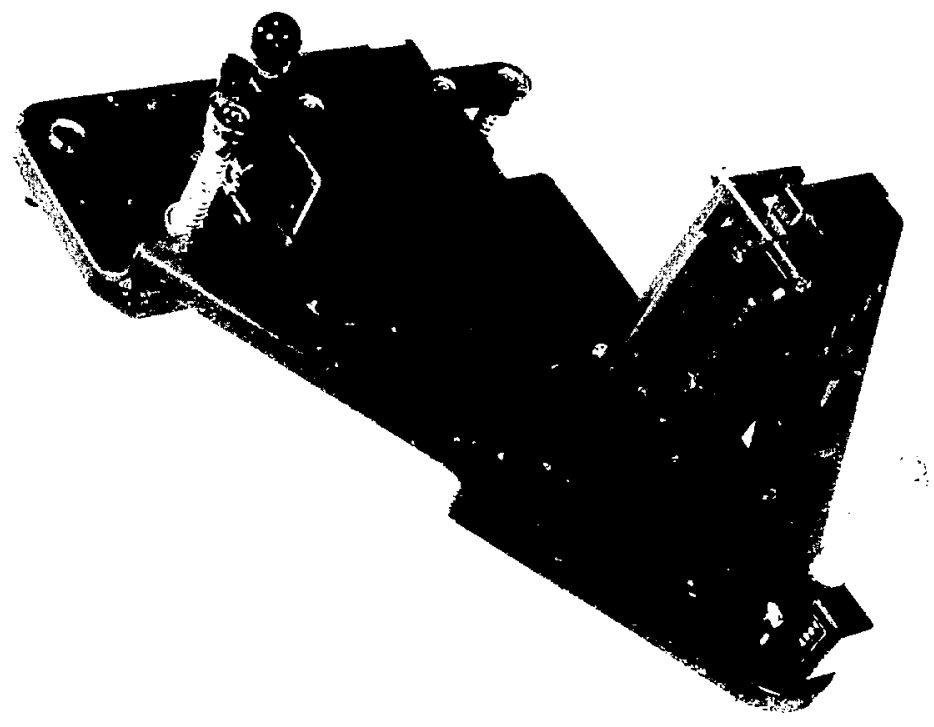

Fig. 11. Bend magnet fixture. 


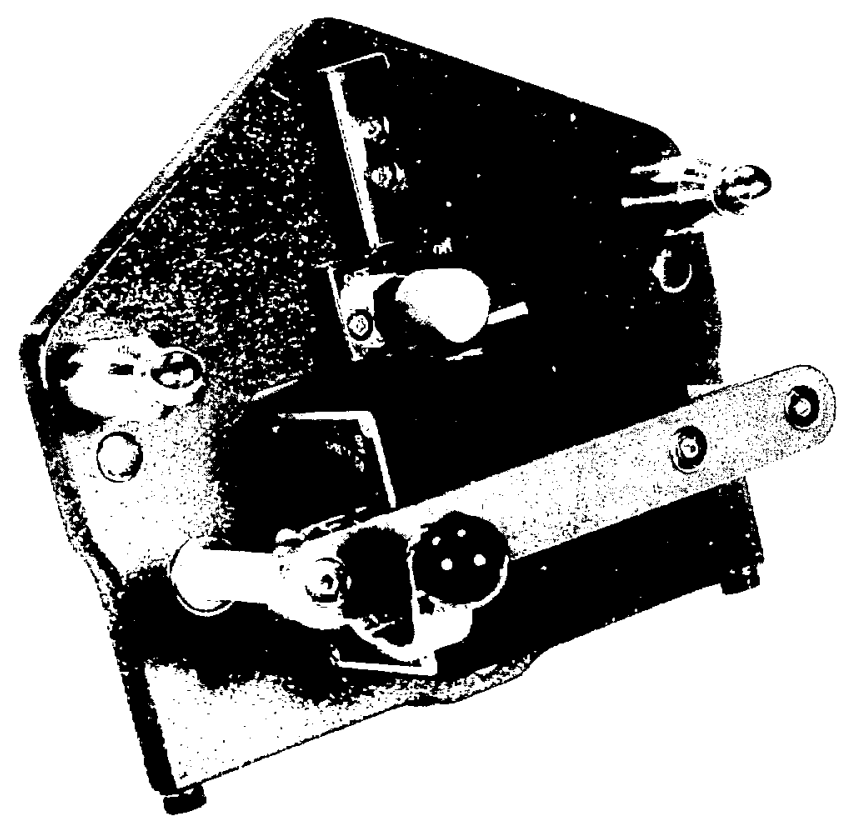

Fig. 12. Quadrupole magnet fixture. 
$-76-$

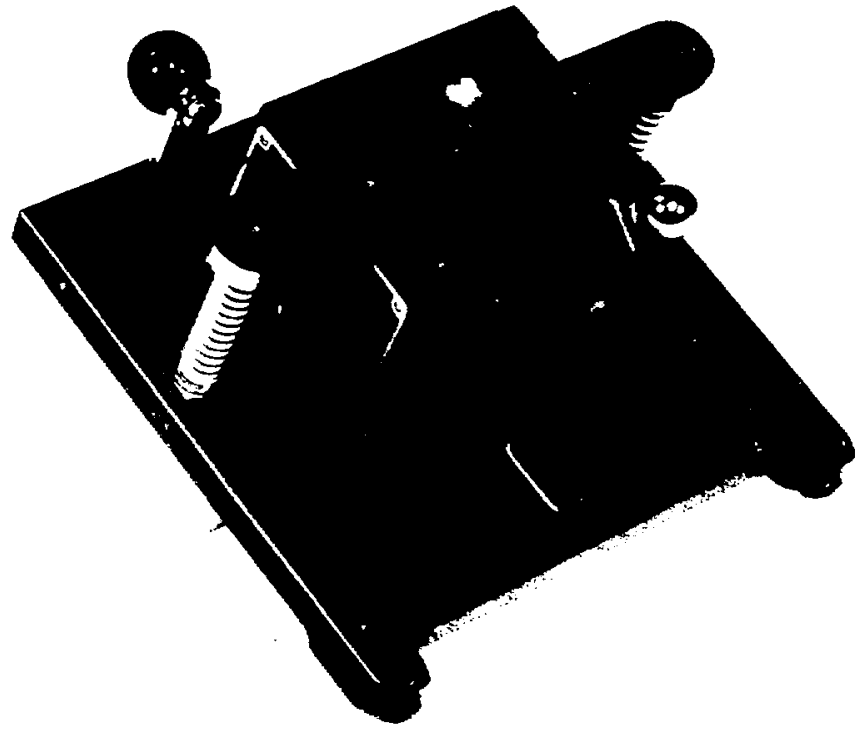

Fig. 13. Sextupole magnet fixture. 


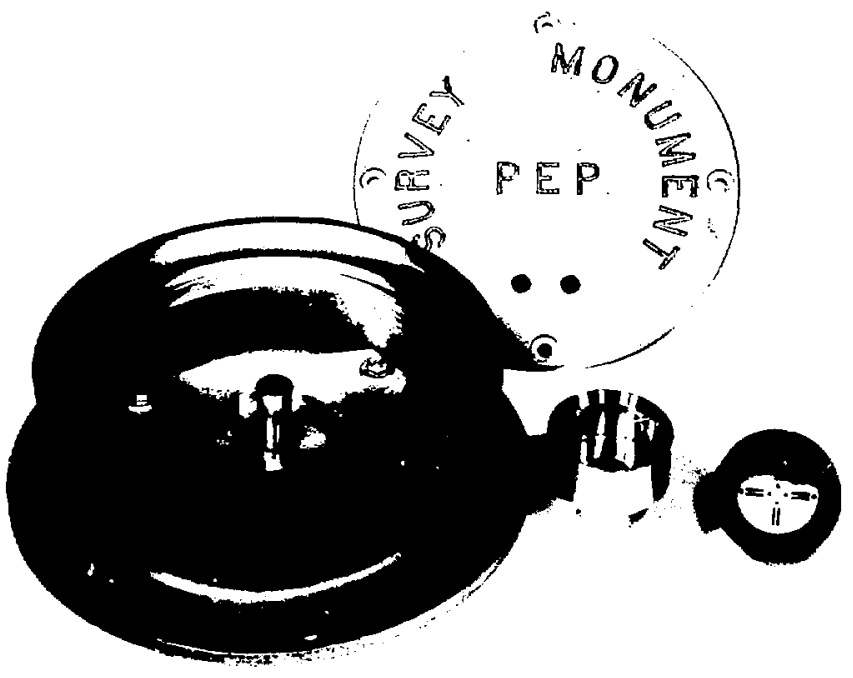

Fig. 14. Monument components, optical tooling sphere. 


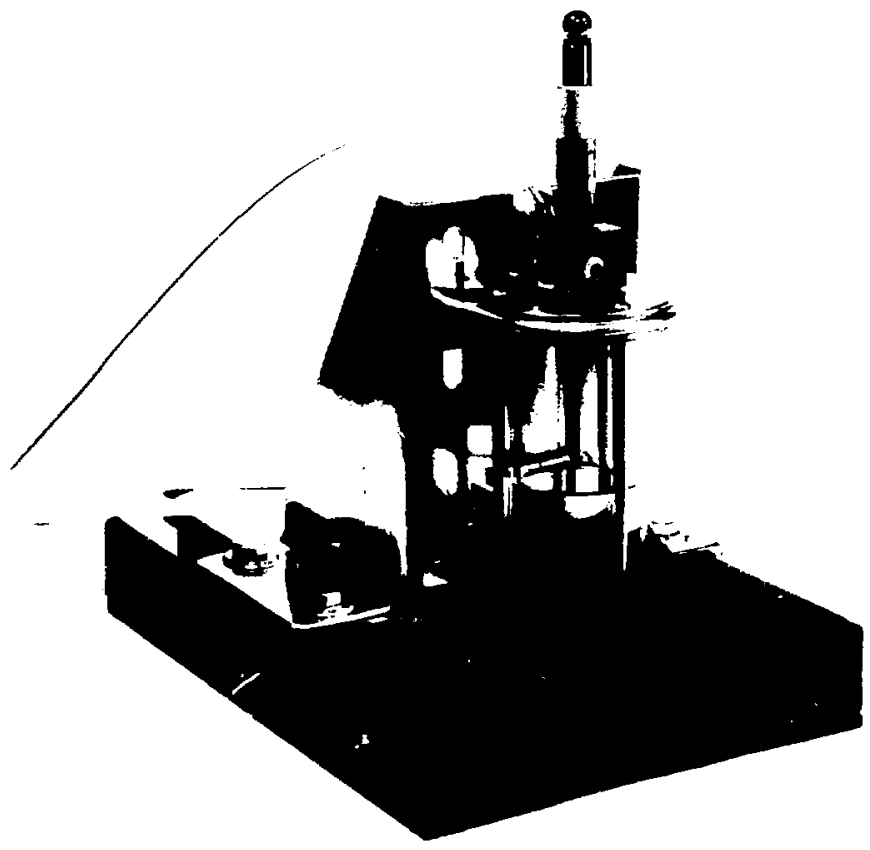

fig. 15. Liquid Level Well and stand. 


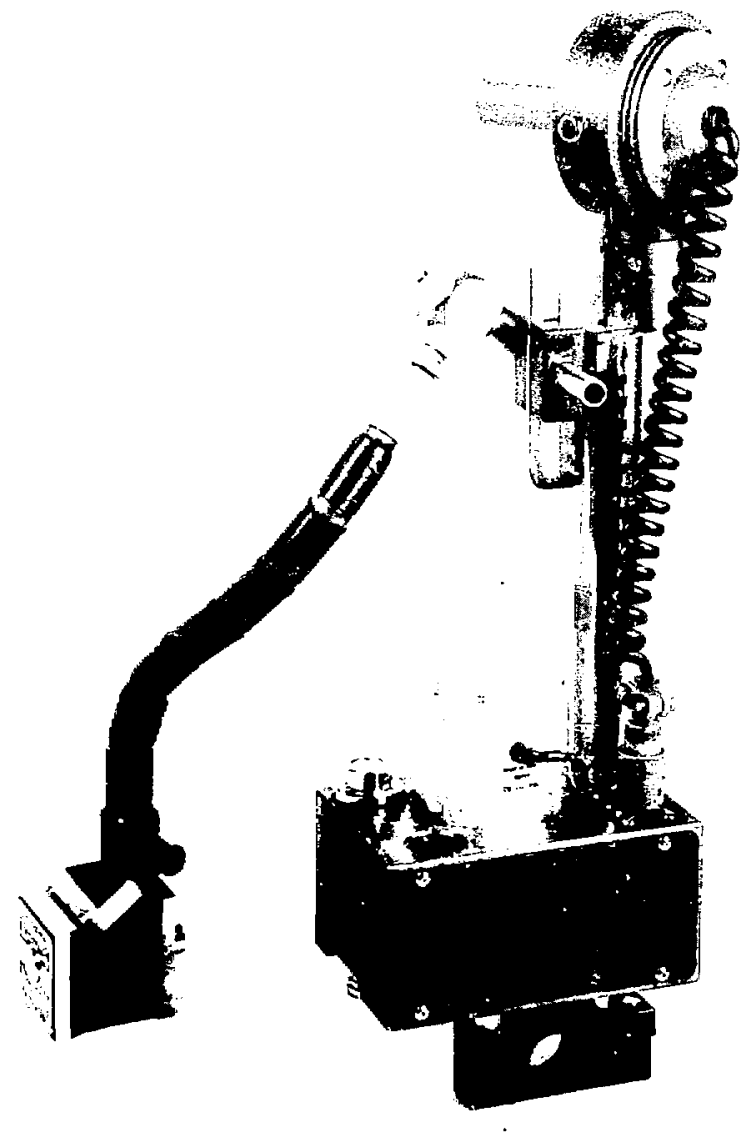

Fig. 16. Small Automatic Micrometer (SAM). 


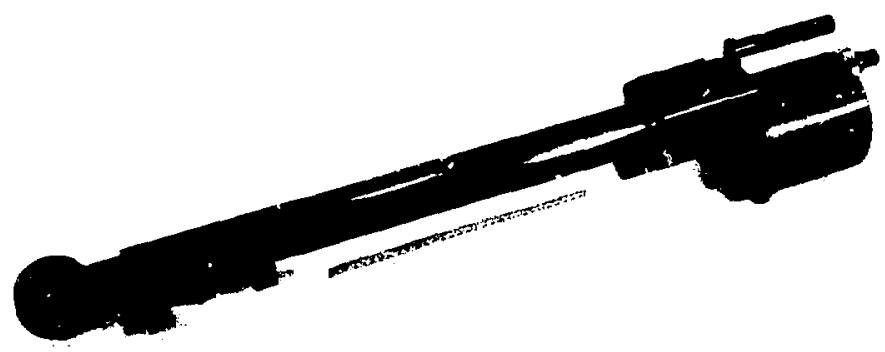

Fig. 17. Automatic Readout Micrometer (ARM). 


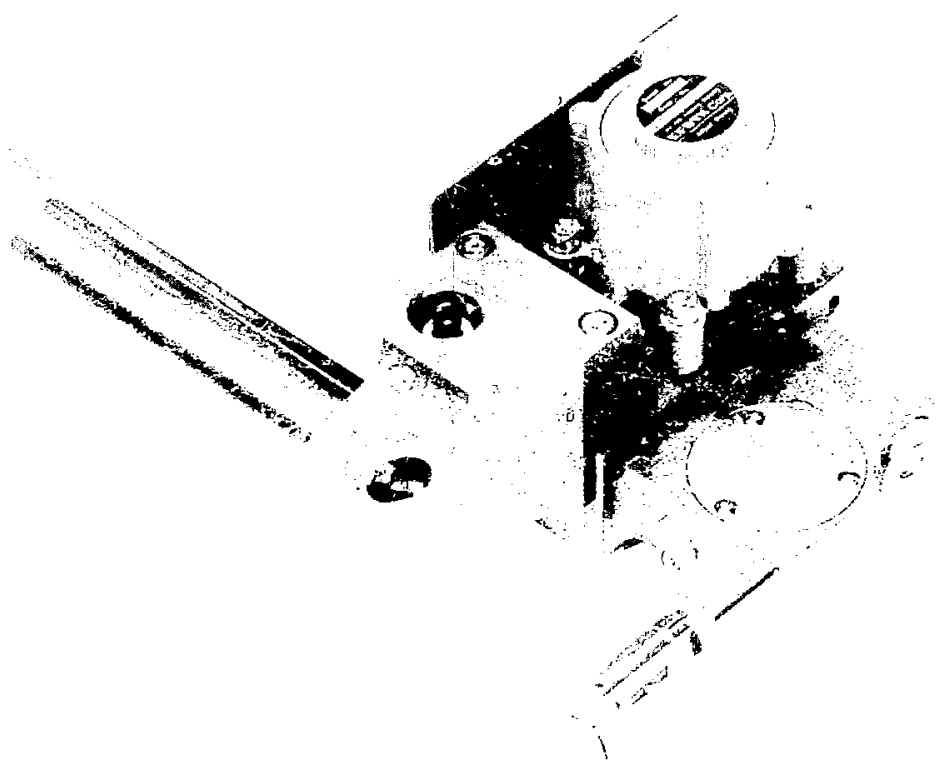

Fig. 18. Automatic keadout Tape Urit (ARTU). 